\title{
ENHANCED SUPERCAPACITIVE PERFORMANCE OF NANOCRYSTALLINE Mn3O4 SYNTHESIZED BY HYDROTHERMAL METHOD
}

\author{
Dadamiah PMD Shaik ${ }^{a}$, P. Rosaiah ${ }^{b}$ and O M Hussain*
}

a. Department of Physics, Sree Vidyanikethan Engineering College, A. Rangampeta, Tirupathi, Andhra

Pradesh, India

rahilsp@gmail.com

b, ${ }^{*}$. Department of Physics, Thin film Laboratory, S V University, Tirupathi, Andhra Pradesh, India

\section{ABSTRACT}

hussainsvu@gmail.com

\begin{abstract}
$\mathrm{Mn}_{3} \mathrm{O}_{4}$ nanoparticles have been successfully synthesized by a simple hydrothermal method at low temperatures. The processing conditions such as reaction temperature and time were optimized to synthesized phase pure nanocrystalline $\mathrm{Mn}_{3} \mathrm{O}_{4}$ with good electrochemical properties. The particles synthesized at a reaction temperature of $150^{\circ} \mathrm{C}$ for $12 \mathrm{~h}$ exhibited different characteristic peaks along with (211) predominant orientation which corresponds to tetragonal structure of $\mathrm{Mn}_{3} \mathrm{O}_{4}$ with space group $14_{1} /$ amd (141) and estimated crystallite size of $32 \mathrm{~nm}$. The SEM analysis reveals that the octahedral shape of grains with an average grain size of $180 \mathrm{~nm}$. The vibrational studies from Raman and FTIR measurements confirmed the microstructure and presence of $\mathrm{Mn}-\mathrm{O}$ bonding. The conductivity of the product was increased with increasing temperature following the Arrhenius behavior with estimated activation energy of $0.37 \mathrm{eV}$. The supercapacitive performance of nanocrystalline $\mathrm{Mn}_{3} \mathrm{O}_{4}$ octahedrons in $1 \mathrm{M} \mathrm{Na} \mathrm{SO}_{4}$ aqueous electrolyte exhibited a high specific capacitance of $348 \mathrm{Fg}^{-1}$ at current density of $0.5 \mathrm{mAcm}^{-2}$ and $70 \%$ capacitive retention even after 4000 cycles.
\end{abstract}

Keywords:- $\mathrm{Mn}_{3} \mathrm{O}_{4}$ nanoparticles; hydrothermal method; activation energy; specific capacitance

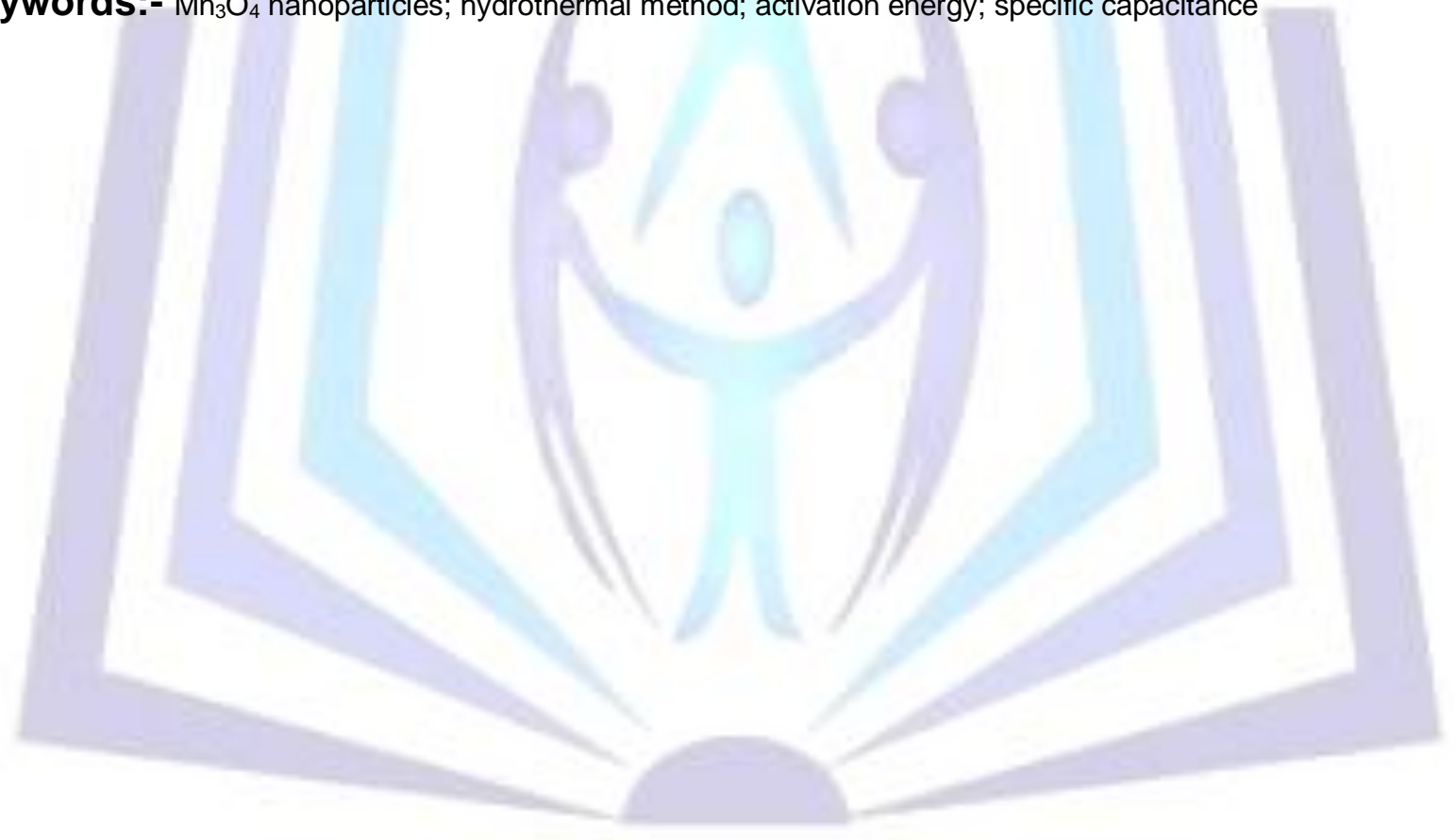

\section{Council for Innovative Research}

Peer Review Research Publishing System

\section{Journal: Journal of Advances in Chemistry}

Vol. 12, No. 1

www.cirjac.com

editorjaconline@gmail.com, editor@cirjac.com 


\section{Introduction:}

In recent days, the development of electrical energy storage devices is a very big challenge to meet the future energy requirements for microelectronic devices. Supercapacitors are the type of energy storage devices that have the advantages of high power density, friendly environment, high safety and convenient operation over a wide range of temperature. Supercapacitors are classified into two types based on charge storage mechanism as Electric Double Layer Capacitors (EDLC) and pseudo capacitors. The charge storage in EDLC is due to the accumulation of charges at electrode and electrolyte interface and in pseudo capacitors, it is due to the charge transfer from reversible Faradic reactions that takes place on the electrode surface. The performance of supercapacitors depends on the properties of electrode material used. Hence, many researchers were focused in development of new electrode materials for supercapacitors from the past few decades. In this perspective, activated carbon [1], Carbon Nano Tubes [2], conducting polymers [3,4], and transition metal oxides [5] were used as electrode material for supercapacitor applications. Among these electrode materials, transition metal oxides play a very important role due to their high redox pseudo capacitance and chemical stability. Several transition metal oxides were used as the electrode materials for supercapacitors, such as $\mathrm{RuO}_{2}$ [6], $\mathrm{Co}_{3} \mathrm{O}_{4}$ [7], $\mathrm{NiO}$ [8], $\mathrm{SnO}_{2}$ [9], $\mathrm{CuO}$ [10] and oxides of manganese [11-13]. Among these electrode materials, $\mathrm{RuO}_{2}$ was the most widely studied material due to its high specific capacitance, high conductivity and excellent chemical stability. However, due to its high cost, less abundance and toxicity the usage of $\mathrm{RuO}_{2}$ becomes difficult for practical applications. Manganese oxides with different crystalline structures become alternate electrode materials for supercapacitor applications due to their high theoretical specific capacitance, high power density, environmentally friendly nature, natural abundance, low cost and long term cyclic stability [14]. Manganese oxide crystallizes into $\mathrm{MnO}, \mathrm{Mn}_{3} \mathrm{O}_{4}$, $\mathrm{Mn}_{2} \mathrm{O}_{3}$ and $\mathrm{MnO}_{2}$ due to the existence of three kinds of oxidation states of manganese $\left(\mathrm{Mn}^{2+}, \mathrm{Mn}^{3+}, \mathrm{and} \mathrm{Mn}^{4+}\right)$. Among these forms of manganese oxides, $\mathrm{Mn}_{3} \mathrm{O}_{4}$ is one of the most stable and it has a variety of important applications in different areas including rechargeable lithium ion batteries, molecular adsorption, electrochemistry, magnetic and supercapacitors [15-18].

So far, $\mathrm{Mn}_{3} \mathrm{O}_{4}$ nanoparticles were prepared and their supercapacitive behavior has been studied by many researches. For example, $\mathrm{K}$ Vijaya Shankar et al [19] prepared of $\mathrm{Mn}_{3} \mathrm{O}_{4}$ nanoparticles using microwave assisted reflux synthesis method which exhibited specific capacitance of $74 \mathrm{Fg}^{-1}$ at a current density of $0.5 \mathrm{mAcm}^{-2}$ in $6 \mathrm{M} \mathrm{KOH}$. YANG Lu-Feng el al [20] reported a specific capacitance of $173 \mathrm{Fg}^{-1}$ at $0.2 \mathrm{Ag}^{-1}$ in $0.5 \mathrm{M} \mathrm{Na} \mathrm{SO}_{4}$ for $\mathrm{Mn}_{3} \mathrm{O}_{4} \mathrm{Polyhedral}$ nanocrystrals prepared by solution based thermolysis process. $\mathrm{H}$. Jiang et al [21] using hydrothermal synthesis prepared $\mathrm{Mn}_{3} \mathrm{O}_{4}$ nano-octahedrons with specific capacitance of $322 \mathrm{Fg}^{-1}$ at a scan rate of $5 \mathrm{mVs}^{-1}$ in $1 \mathrm{M} \mathrm{Na}_{2} \mathrm{SO}_{4}$. A high specific capacitance of $322 \mathrm{Fg}^{-1}$, with $77 \%$ of capacitance retention after 1000 cycles was reported by B Gnana Sundara Raj et al [22] for $\mathrm{Mn}_{3} \mathrm{O}_{4}$ nanospheres synthesized by chemical precipitation approach at a current density of $0.5 \mathrm{mAcm}^{-2}$ in $1 \mathrm{M}$ $\mathrm{Na}_{2} \mathrm{SO}_{4}$

The supercapacitive perforamance of electrode materials mainly relies on size, shape, specific surface area, electrical conductivity, porous structure and crystalline nature which in turn depend on preparation methods. Among all chemical methods used for the preparation of $\mathrm{Mn}_{3} \mathrm{O}_{4}$ nanoparticles, hydrothermal method is one of the best methods because it has a unique advantage of low temperature reaction and ability to create crystalline phases which are stable and particularly for the growth of good quality and control over their composition. Therefore, in the present investigation, hydrothermal method has been employed to synthesize $\mathrm{Mn}_{3} \mathrm{O}_{4}$ crystalline particles with lower dimensions. It is noted that in hydrothermal method the particle size, shape and morphology of $\mathrm{Mn}_{3} \mathrm{O}_{4}$ are influenced by reaction temperature and time. Hence, a detailed investigation has been carried out to understand the influence of reaction temperature and time on the growth of $\mathrm{Mn}_{3} \mathrm{O}_{4}$. It is demonstrated that the nanocrystalline $\mathrm{Mn}_{3} \mathrm{O}_{4}$ electrode synthesized at $150^{\circ} \mathrm{C}$ for $12 \mathrm{~h}$ exhibited superior performance with high specific capacitance and excellent capacitive retention during cycling.

\section{Experimental Procedure:}

Manganese Chloride $(\mathrm{MnCl} 2.4 \mathrm{H} 2 \mathrm{O})$ and Sodium Hydroxide $(\mathrm{NaOH})$ were obtained from Merck co. and used without further purification. The solutions were prepared using double distilled (DD) water. In a typical preparation, $3.96 \mathrm{~g}(1 \mathrm{M})$ of $\mathrm{MnCl} 2.4 \mathrm{H} 2 \mathrm{O}$ was dissolved in $20 \mathrm{ml}$ of $\mathrm{DD}$ water and $0.8 \mathrm{~g}(1 \mathrm{M})$ of $\mathrm{NaOH}$ was dissolved in $20 \mathrm{ml}$ of DD water in separate beakers. The solution of manganese chloride was slowly added drop wise to the solution of sodium hydroxide under continuous stirring. The resultant solution was taken in a $50 \mathrm{ml}$ Teflon lined stainless steel autoclave and kept at various temperatures $\left(60^{\circ} \mathrm{C}-180^{\circ} \mathrm{C}\right)$ and times $(1 \mathrm{~h}-24 \mathrm{~h})$ in oven. The brown precipitates of $\mathrm{Mn3O} 4$ were formed in the following steps

$\begin{array}{ll}\mathrm{MnCl}_{2}+2 \mathrm{NaOH} & \longrightarrow \mathrm{Mn}(\mathrm{OH})_{2}+2 \mathrm{NaCl} \\ \mathrm{Mn}(\mathrm{OH})_{2} & \longrightarrow+\mathrm{H}_{2} \mathrm{O} \\ 3 \mathrm{MnO}+1 / 2 \mathrm{O}_{2} & \longrightarrow \quad \mathrm{Mn}_{3} \mathrm{O}_{4}\end{array}$

The autoclave was cooled to room temperature, brown precipitates were collected with centrifuge and cleaned with distilled water and ethanol for several times to remove the impurities followed by drying at $60^{\circ} \mathrm{C}$ for $24 \mathrm{~h}$.

Material Characterization:

The structural properties of as prepared nanocrystals were studied by Seifert X-ray diffractometer (Model 3003 TT ) using $\mathrm{CuK}_{\alpha}(\lambda=0.154 \mathrm{~nm})$ radiation source filtered by Ni thin film at a scan speed of $0.05^{\circ}$ per second in the $2 \theta$ range $20^{\circ}-80^{\circ}$ and by Raman Spectroscopy using Horiba Jobin Yvon LabRAM HR800UV Raman Spectrometer with He-Ne laser $532 \mathrm{~nm}$ as an excitation wavelength. The morphology and chemical composition of the sample was analysed from carl 
ZEISS (Model EVO MA15) in high vacuum and the chemical composition of the sample was analyzed by EDAX system (Oxford Instruments, UK)

Electrical studies:

The powder was pressed into $12 \mathrm{~mm}$ diameter pellet with $1 \mathrm{~mm}$ thickness and then annealed at $300^{\circ} \mathrm{C}$ for $4 \mathrm{~h}$. Silver paste is coated on both sides of the pellet for electrical measurements. The conductivity measurements were recorded on N4L PSM 1700, UK over the frequency range of $1 \mathrm{~Hz}$ to $1 \mathrm{MHz}$ in the temperature range from room temperature to $373 \mathrm{~K}$.

Electrochemical studies:

Firstly, working electrode was prepared from the mixture of $\mathrm{Mn}_{3} \mathrm{O}_{4}$ powder $(80 \%)$, carbon black (10\%) and Poly Vinylidene Fluoride (10\%) as binder. The above mixture was grinded for half an hour and then the homogenous slurry was made using N-methyl-2-pyrrolidone as a solvent. The slurry was subsequently brush-coated onto a chemically cleaned stainless steel plate. The electrode was dried at $100^{\circ} \mathrm{C}$ in air for $2 \mathrm{~h}$ for the removal of the solvent.

A three electrode glass cell equipped with a $\mathrm{Mn}_{3} \mathrm{O}_{4}$ working electrode, a platinum foil as counter and reference electrode and $1 \mathrm{M} \mathrm{Na}_{2} \mathrm{SO}_{4}$ as electrolyte used to study electrochemical behavior of $\mathrm{Mn}_{3} \mathrm{O}_{4}$ nanoparticles. The electrochemical properties were examined on $\mathrm{CHI} 608 \mathrm{C}$ electrochemical analyzer.

\section{Result and Discussion:}

\subsection{Microstructural Properties:}

3.1.1. XRD Analysis:

Fig. $1 \mathrm{a}$ and $1 \mathrm{~b}$ show the $\mathrm{X}$-ray powder diffraction spectra of $\mathrm{Mn}_{3} \mathrm{O}_{4}$ nanoparticles recorded in the diffraction angle $25^{\circ}-70^{\circ}$ at different reaction temperatures $\left(60^{\circ} \mathrm{C}-180^{\circ} \mathrm{C}\right)$ and times $(1 \mathrm{~h}-24 \mathrm{~h})$ respectively. The reaction was found to be incomplete below $150^{\circ} \mathrm{C}$ temperature. At temperature $150^{\circ} \mathrm{C}$, the product exhibited predominant diffraction peak (211) along with characteristic (112), (200), (103), (004), (220), (204), (105), (312), (303), (321), (224), (440), (305), (413), (422), (404) peaks which corresponds to tetragonal structure of $\mathrm{Mn}_{3} \mathrm{O}_{4}$ with $14_{1} /$ amd(141) space group (JCPDS card No.894837). No other impurity peaks were detected in the spectra. By further increasing the reaction temperature, two impurities peaks at Bragg angle $29.15^{\circ}$ and $37^{\circ}$ were observed which belong to $\mathrm{MnO}_{2}$ [23]. From Fig $1 \mathrm{~b}$ it is observed that the peak intensities increased and the width of the peaks decreased as a function of reaction time. The coherent length $\left(L_{c}\right)$ which corresponds to the crystallite size of the sample was calculated from the predominant (211) diffraction peak for different reaction times using the following Debye-Scherrer's formula

Where, $k$ is the Scherer's constant $(0.94), \lambda$ is the wavelength of $X$ ray radiation $(1.5406 \AA \hat{)}), \beta$ is the full width at half maximum (FWHM) measured in radian and ' $\theta$ ' is the corresponding Bragg angle. The calculated crystallite size was observed to be increased from $13 \mathrm{~nm}$ to $65 \mathrm{~nm}$ by increasing the reaction time from $1 \mathrm{~h}$ to $24 \mathrm{~h}$ (Fig. 1c).

Vibrational studies:

The Raman spectroscopy is an effective characterization technique to investigate structure and chemical composition of the sample. The Raman spectra of the $\mathrm{Mn}_{3} \mathrm{O}_{4}$ nanoparticles were recorded in the range $300-900 \mathrm{~cm}^{-1}$ for different reaction times at $150^{\circ} \mathrm{C}$ as shown in Fig. 2. The common future of these spectra is the presence of strong band around $650 \mathrm{~cm}^{-1}$ and a group of bands between $200 \mathrm{~cm}^{-1}-500 \mathrm{~cm}^{-1}$ with weaker intensity [24]. The main peak located at $654 \mathrm{~cm}^{-1}$ corresponds to the $\mathrm{Mn}-\mathrm{O}$ stretching vibrations (single degenerate $\mathrm{A}_{1 \mathrm{~g}}$ symmetry mode) of $\mathrm{Mn}^{2+}$ in tetrahedral coordination. The two other peaks at $317 \mathrm{~cm}^{-1}$ and $360 \mathrm{~cm}^{-1}$ are assigned to the out of plane bending modes of $\mathrm{Mn}-\mathrm{O}\left(\mathrm{E}_{g}\right.$ symmetry mode) and asymmetric stretch of bridge oxygen species Mn-O-Mn respectively. One weak band at $462 \mathrm{~cm}^{-1}$ is attributed to doubly degenerate $T_{2 g}$ symmetry mode. All the peaks in the spectrum which are the representative for the tetragonal structure of $\mathrm{Mn}_{3} \mathrm{O}_{4}$. But, at lower reaction temperatures, the strong peak at $654 \mathrm{~cm}^{-1}$ shifted and broadened. The red shift of the peak and peak broadening was mainly due to grain size effect $[25,26]$.

The vibrational studies of $\mathrm{Mn}_{3} \mathrm{O}_{4}$ sample was also examined by FTIR within the wavenumber range of 2000-350 $\mathrm{cm}^{-1}$ at a reaction temperature of $150^{\circ} \mathrm{C}$ for $12 \mathrm{~h}$ in order to know the chemical bonds present in $\mathrm{Mn}_{3} \mathrm{O}_{4}$ sample and is shown in Fig 3. The two broad peaks at $610 \mathrm{~cm}^{-1}$ and $523 \mathrm{~cm}^{-1}$ are associated with the Mn-O stretching mode of tetrahedral and octahedral site respectively. In addition, one broad absorption peak at $443 \mathrm{~cm}^{-1}$ is attributed to vibration of manganese species in an octahedral site. The absorption peaks $1527 \mathrm{~cm}^{-1}$ and $1038 \mathrm{~cm}^{-1}$ may be attributed to $\mathrm{O}-\mathrm{H}$ bending vibration combined with $\mathrm{Mn}$ atoms [27]. Thus, FTIR result shows the presence of $\mathrm{Mn}-\mathrm{O}$ bonds confirming the formation of the $\mathrm{Mn}_{3} \mathrm{O}_{4}$ product.

\subsubsection{SEM Analysis:}

The effective surface area of the materials mainly depends on the size and shape of the nanoparticles which is very important for supercapacitor applications. The $\mathrm{Mn}_{3} \mathrm{O}_{4}$ sample morphology was analyzed using SEM at reaction temperature of $150^{\circ} \mathrm{C}$ for three different reaction times as shown in Fig.4. At a reaction time of $1 \mathrm{~h}$, the sample consists of agglomerated nanograins with an average grain size of $100 \mathrm{~nm}$. By increasing the reaction time from $1 \mathrm{~h}$ to $12 \mathrm{~h}$, it is observed that the powder is composed of uniformly distributed octahedral shaped nanograins with an estimated average grain size of $180 \mathrm{~nm}$ (Fig4b). It can be clearly seen that the overlapped octahedral grains in inset of fig 4b. Further increasing the reaction time, the truncated octahedral shape of the particles was observed with increased size (Fig4d). The particle size obtained from SEM data is generally larger than the crystallite size obtained from XRD studies, so that 
the primary particle size should not be confused with crystallite size. It may be noted that during the synthesis, the particles might have been assembled into primary particles with an average size of $180 \mathrm{~nm}$ [28].

The chemical composition of the sample has been carried out using EDAX measurement as shown in Fig.5. It exhibited corresponding binding energy peaks of $\mathrm{Mn}$ and $\mathrm{O}$ present in the sample and no other impurity peaks are detected in the spectrum which indicates the high chemical purity of the sample and the estimated compositions of Mn and $\mathrm{O}$ are $71.39 \%$ and $28.61 \%$ respectively.

\subsubsection{Electrical Properties:}

The impedance response of $\mathrm{Mn}_{3} \mathrm{O}_{4}$ sample was studied from Cole-Cole plots at different temperatures as shown in Fig. 6. These plots allow the resistances related to grain interiors (bulk), grain boundaries and sample/electrode interfaces to be separated because each of them has different relaxation time, resulting in separate semicircles in the complex impedance plane. The relaxation frequency for the bulk is greater than the relaxation frequency for grain boundaries and the relaxation frequency resulting from the electrode process is much smaller than relaxation frequency of grain boundaries. As the temperature increases, all semicircles become smaller and shift towards higher-frequency region, indicating a reduction of grain $\left(R_{\mathrm{g}}\right)$ and grain boundary resistance $\left(R_{\mathrm{rb}}\right)$.

The temperature dependence of electrical conductivity in the range from room temperature to $373 \mathrm{~K}$ is as shown in Fig.7. It is clear that the conductivity increases with increasing temperature indicating semiconducting behavior of $\mathrm{Mn}_{3} \mathrm{O}_{4}$ sample [29]. The electrical conductivity $(\sigma)$ of $\mathrm{Mn}_{3} \mathrm{O}_{4}$ at $373 \mathrm{~K}$ was calculated using the formula $\sigma=t / \mathrm{R}_{\mathrm{b}} \mathrm{A}$, $\mathrm{Sm}^{-1}$ and is found to be $1.86 \times 10^{-5} \mathrm{Sm}^{-1}$. Here, $t$ is the thickness of the sample, $\mathrm{R}_{\mathrm{b}}$ is the bulk resistance of the sample and $A$ is the effective area. The conductivity data is fitted using the Arrhenius equation, $\sigma=\sigma_{0} \exp \left(-E_{a} / k_{B} T\right)$, Here, $\sigma_{0}$ is the pre exponential factor, $E_{a}$ is activation energy in $\mathrm{eV}, \mathrm{k}_{\mathrm{B}}$ is Boltzmann constant and $\mathrm{T}$ is absolute temperature respectively. The activation energy was calculated from the above equation and is found to be $0.37 \mathrm{eV}$ [30].

\subsubsection{Electrochemical properties:}

The electrochemical properties of $\mathrm{Mn}_{3} \mathrm{O}_{4}$ nanoparticles were studied using Cyclic Voltammetry (CV), Chronopotentiometry(CP) and Electrochemical Impedence Spectroscopy (EIS) with three electrode glass cell equipped with a $\mathrm{Mn}_{3} \mathrm{O}_{4}$ working electrode and platinum as counter and reference electrode in $1 \mathrm{M} \mathrm{Na}_{2} \mathrm{SO}_{4}$ aqueous electrolyte. Fig.8a shows the cyclic voltammograms of the $\mathrm{Mn}_{3} \mathrm{O}_{4}$ nanoparticles at different scan rates from 1-50 $\mathrm{mVs}^{-1}$ in the potential range $-0.1 \mathrm{~V}$ to $+0.9 \mathrm{~V}$ vs. Pt. It is observed that all the $\mathrm{CV}$ curves exhibited mirror image characteristics, which indicates that the Faraday redox reactions are electrochemically reversible representing an ideal electrochemical capacitor behavior. And also observed that the current under the curves is directly proportional to scan rate. The cycling performance is also important for electrochemical supercapacitor applications. The cyclic performance of $\mathrm{Mn} 3 \mathrm{O} 4$ electrode was studied from CV up to 1000 cycles at two different scan rates of $10 \mathrm{mVs}^{-1}$ and $20 \mathrm{mVs}^{-1}$ as is shown in Fig.8b. The CV curves are almost similar even after 1000 cycles indicates the $\mathrm{Mn}_{3} \mathrm{O}_{4}$ electrode has high structural stability.

The galvanostatic charge-discharge cycling studies were carried out in $1 \mathrm{M} \mathrm{Na}_{2} \mathrm{SO}_{4}$ aqueous electrolyte in the potential range $-0.1 \mathrm{~V}$ to $+0.9 \mathrm{~V}$ vs. $\mathrm{Pt}$ to know more information about capacitive behavior of $\mathrm{Mn}_{3} \mathrm{O}_{4}$ electrode. $\mathrm{The}^{\mathrm{M}} \mathrm{Mn}_{3} \mathrm{O}_{4}$ nanoparticles show a sudden drop in potential at the starting of discharge [Fig. 9a] due to internal resistance. The linear variation of potential with time indicates the double-layer capacitance behavior, which is caused by the separation of charge at the electrode and electrolyte interface [31]. In addition, the internal resistance of $\mathrm{Mn}_{3} \mathrm{O}_{4}$ electrode increases with increase in current density. The discharge specific capacitance of the sample was calculated from the following formula

$$
C=\frac{I \Delta t}{\Delta V m}
$$

Where $\mathrm{C}$ is specific capacitance in $\mathrm{Fg}^{-1}$, I is galvanostatic discharge current in $\mathrm{A}, \Delta \mathrm{t}$ is the discharge time in $\mathrm{s}, \Delta \mathrm{V}$ is the voltage range in $\mathrm{V}$ and $\mathrm{m}$ is the weight of the active material in the electrode in gram. The specific capacitance values are found to be $348 \mathrm{Fg}^{-1}, 330 \mathrm{Fg}^{-1}, 312 \mathrm{Fg}^{-1}, 298 \mathrm{Fg}^{-1}$ and $286 \mathrm{Fg}^{-1}$ at $0.5 \mathrm{mAcm}^{-2}, 1 \mathrm{mAcm}^{-2}, 2 \mathrm{mAcm}^{-2}, 3 \mathrm{mAcm}^{-2}$ and 5 $\mathrm{mAcm}^{-2}$ respectively. The decrease of specific capacitance with increase in current density may be due to decrease in number of inner active sites of $\mathrm{Mn}_{3} \mathrm{O}_{4}$ electrode contributed to the electrochemical reaction. The capacitive retention of $\mathrm{Mn}_{3} \mathrm{O}_{4}$ electrode is about $82 \%$ with growth of current densities from $0.5 \mathrm{mAcm}^{-2}$ to $5 \mathrm{mAcm}^{-2}$, indicating a good rate capability.

The cycling stability of $\mathrm{Mn}_{3} \mathrm{O}_{4}$ nanoparticles was studied by galvanostatic charge-discharge cycling at a current density of $3 \mathrm{mAcm}^{-2}$ in $1 \mathrm{M} \mathrm{Na}_{2} \mathrm{SO}_{4}$ aqueous electrolyte within the potential range $-0.1 \mathrm{~V}$ to $+0.9 \mathrm{~V}$ vs. Pt as shown in Fig. $9 \mathrm{~b}$ (first 10 cycles). The symmetry characteristic of the charge-discharge curves further support that the electrode has high electrochemical reversibility and excellent capacitive behavior. The specific capacitance decrease with cycle number as shown in Fig. 9c, and attains 70\% capacitive retention after 4000 cycles. The decrease in capacitance is due to the loss of active sites in the electrode material during the early charging/discharging cycles in the electrolyte [12].

The Electrochemical Impedance Spectroscopy (EIS) analysis was carried out in $1 \mathrm{M} \mathrm{Na}_{2} \mathrm{SO}_{4}$ aqueous electrolyte at open circuit potential in the frequency range from $1 \mathrm{~Hz}$ to $1 \mathrm{MHz}$ in order to study the capacitive behavior of the $\mathrm{Mn}_{3} \mathrm{O}_{4}$ electrode material and also to confirm the CV result. The typical Nyquist plots of the $\mathrm{Mn}_{3} \mathrm{O}_{4}$ nanoparticles before and after 4000 cycles are presented in Fig. 10. The intersection made on horizontal axis represents the solution resistance $\left(R_{S}\right)$ at high frequency region. It is observed that the solution resistance was increased from $1.14 \Omega$ to $2.27 \Omega$ after 4000 cycles. A semicircle in high to medium frequency region, which has been termed as a charge transfer resistance $\left(R_{c t}\right)$. The charge transfer resistance of the sample was increased from $30 \Omega$ to $40 \Omega$ after 4000 cycles. The increase in $R_{c t}$ during cycling 
suggests that the specific capacitance decrease with cycle number. The straight line behavior at low frequency region corresponds to Warburg impedance $\left(R_{W}\right)$ or diffusive resistance which indicates the characteristic behavior of supercapacitors.

\section{Conclusion:}

$\mathrm{Mn}_{3} \mathrm{O}_{4}$ nanoparticles were successfully synthesized by a simple and low temperature hydrothermal technique at various reaction temperatures and time without the use of any surfactants for supercapacitor applications. The XRD spectra of $\mathrm{Mn}_{3} \mathrm{O}_{4}$ nanoparticles synthesized at $150^{\circ} \mathrm{C}$ for $12 \mathrm{~h}$, exhibited characteristic peaks along with (211) predominant orientation peak which corresponds to the tetragonal structure of $\mathrm{Mn}_{3} \mathrm{O}_{4}$ with $14_{1} /$ amd (141) space group and the estimated crystallite size of $32 \mathrm{~nm}$. The vibrational studies from Raman and FTIR confirmed the presence of Mn-O bonding. From SEM analysis the morphology of the sample was observed to be changes with reaction time and obtained octahedral shape of grains with an average grain size of $180 \mathrm{~nm}$. The temperature dependent conductivity proves the semiconducting nature of $\mathrm{Mn}_{3} \mathrm{O}_{4}$ nanoparticles and the estimated activation energy is $0.37 \mathrm{eV}$. The electrochemical behavior of $\mathrm{Mn}_{3} \mathrm{O}_{4}$ nanoparticles were investigated using $\mathrm{CV}$, Cronopotentiometry and EIS. The as prepared $\mathrm{Mn}_{3} \mathrm{O}_{4}$ nanoparticles exhibited highest specific capacitance of $348 \mathrm{Fg}^{-1}$ at current density of $0.5 \mathrm{mAcm}^{-2}$ in $1 \mathrm{M} \mathrm{Na}_{2} \mathrm{SO}_{4}$ aqueous electrolyte which may be due to high crystallinity, low particle size and octahedral shape. The superior performance of nanocrystalline $\mathrm{Mn}_{3} \mathrm{O}_{4}$ electrode with $70 \%$ capacitive retention after 4000 cycles has a promising application in supercapacitors.

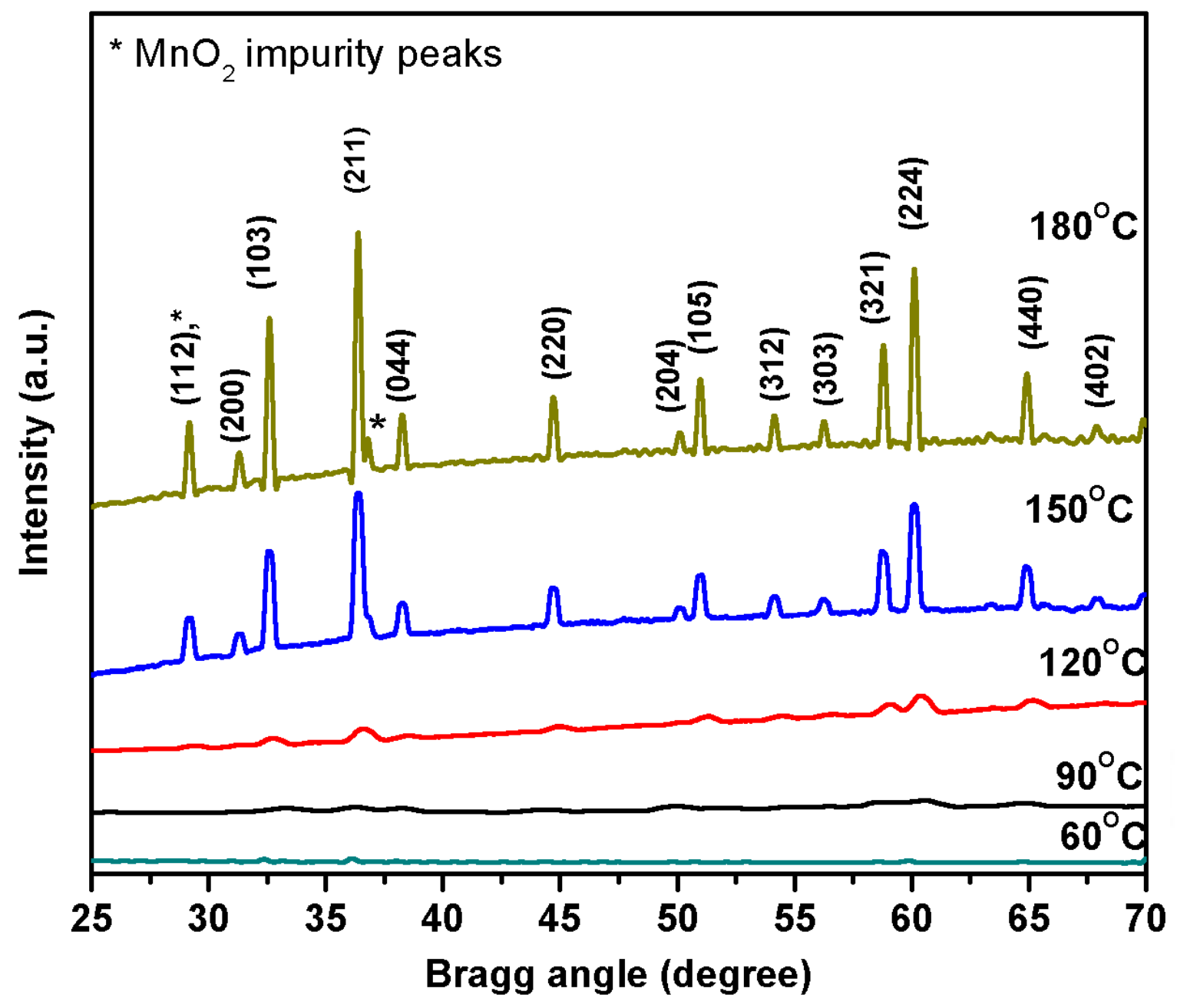

Fig.1a XRD spectrum of $\mathrm{Mn}_{3} \mathrm{O}_{4}$ nanoparticles at different temperatures 


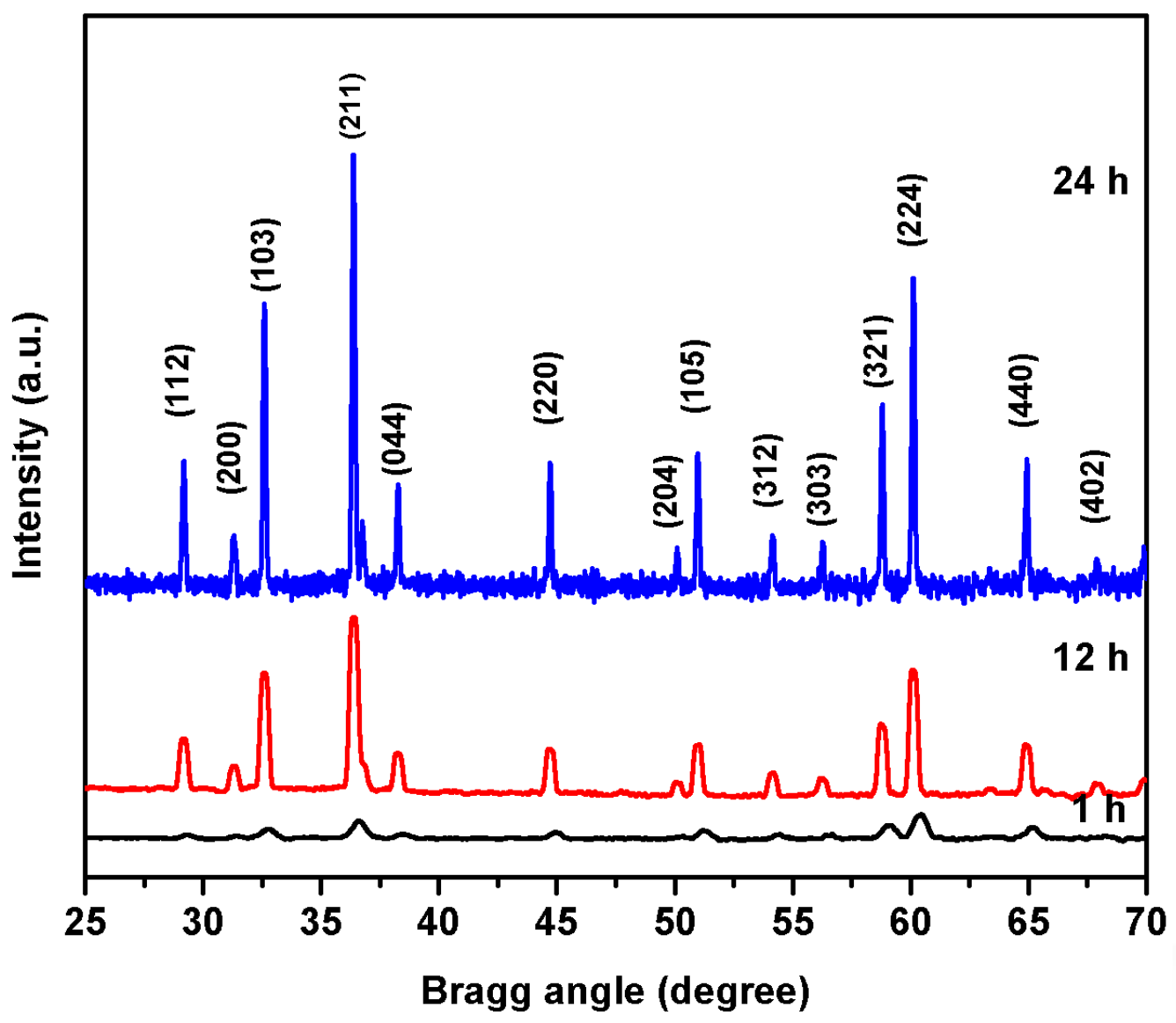

Fig $1 \mathrm{~b} X R D$ at $150^{\circ} \mathrm{C}$ for different reaction times

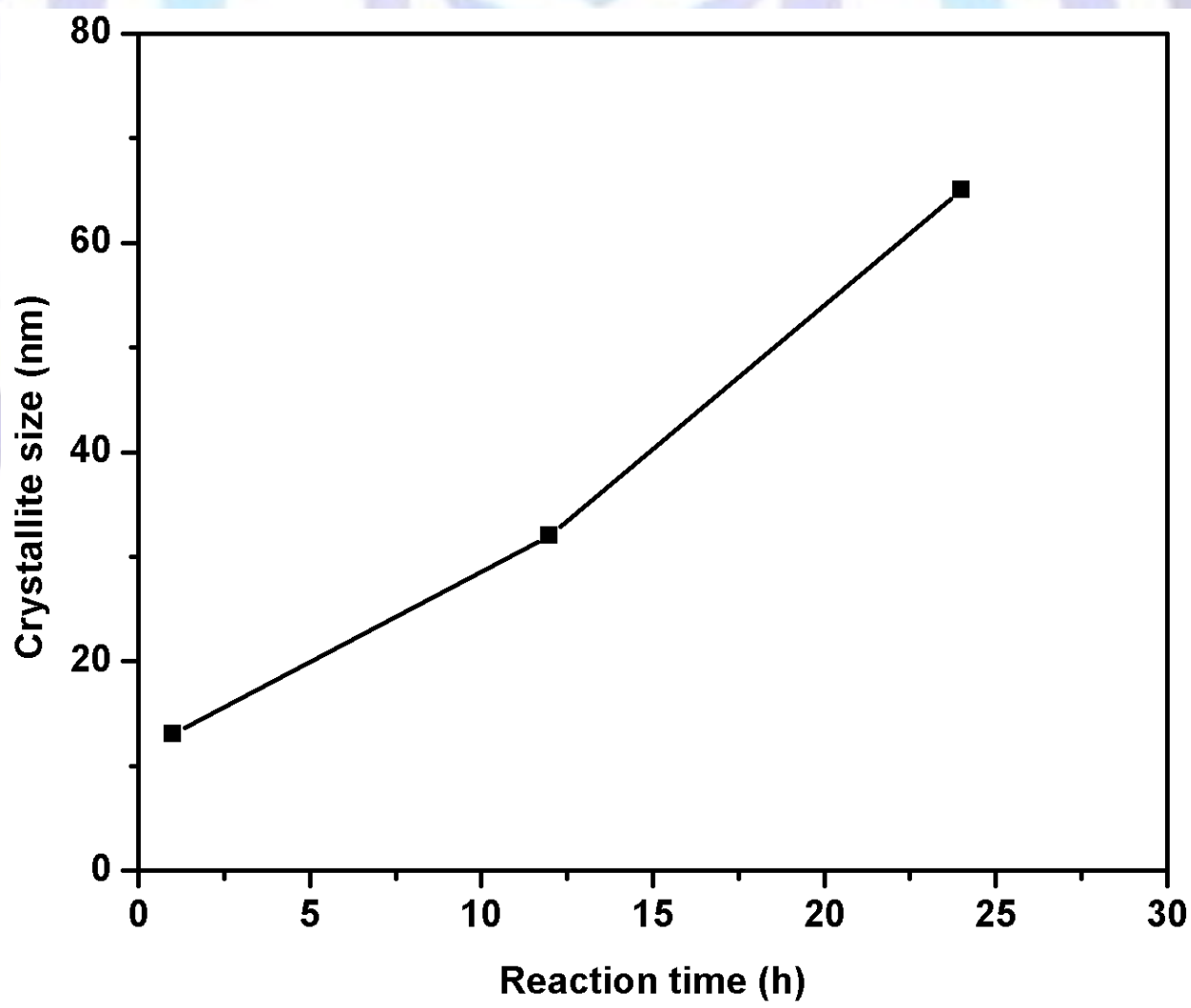

Fig 1c Crystallite size with reaction time at $150^{\circ} \mathrm{C}$ 


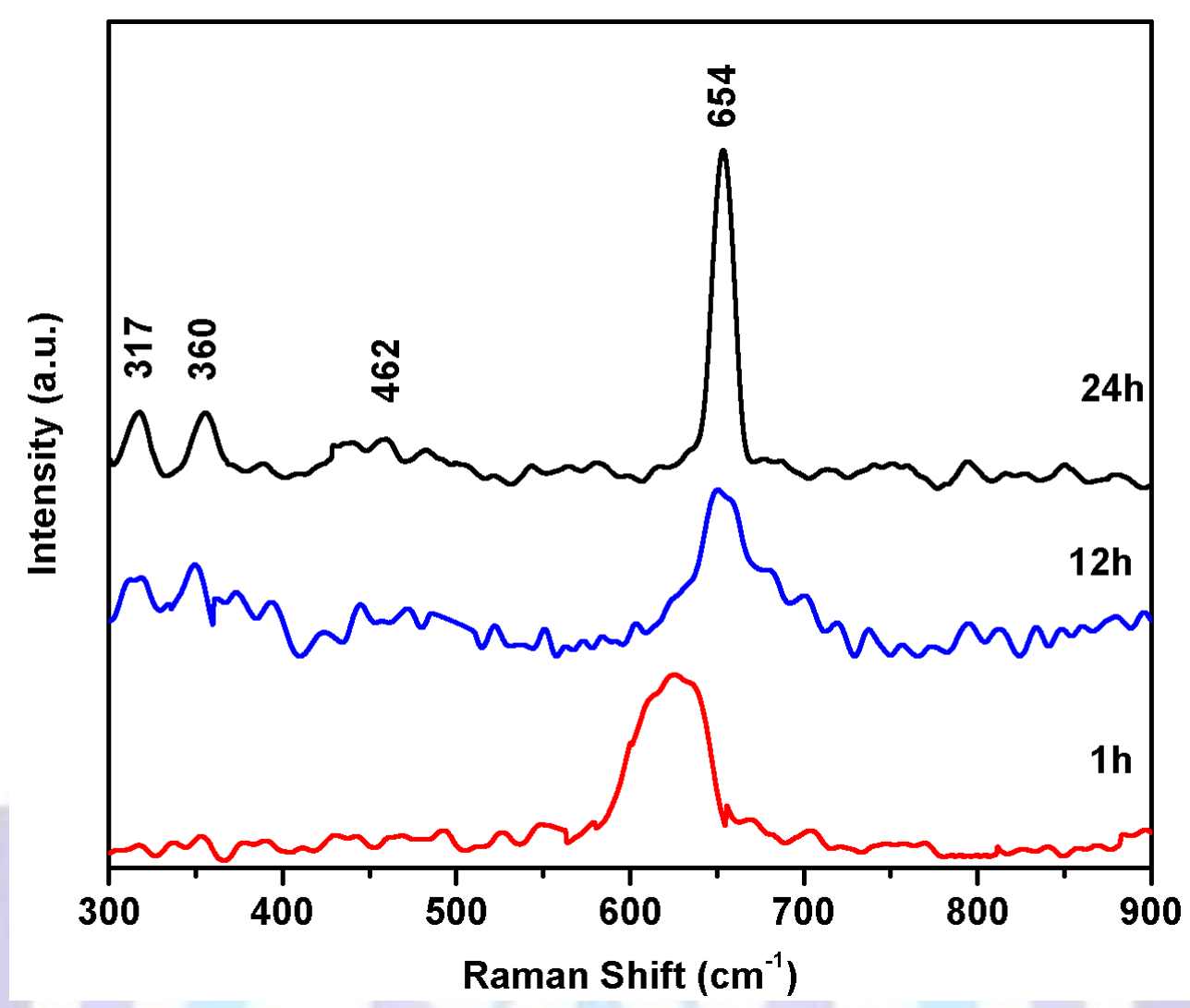

Fig.2 Raman spectra of $\mathrm{Mn}_{3} \mathrm{O}_{4}$ nanoparticles

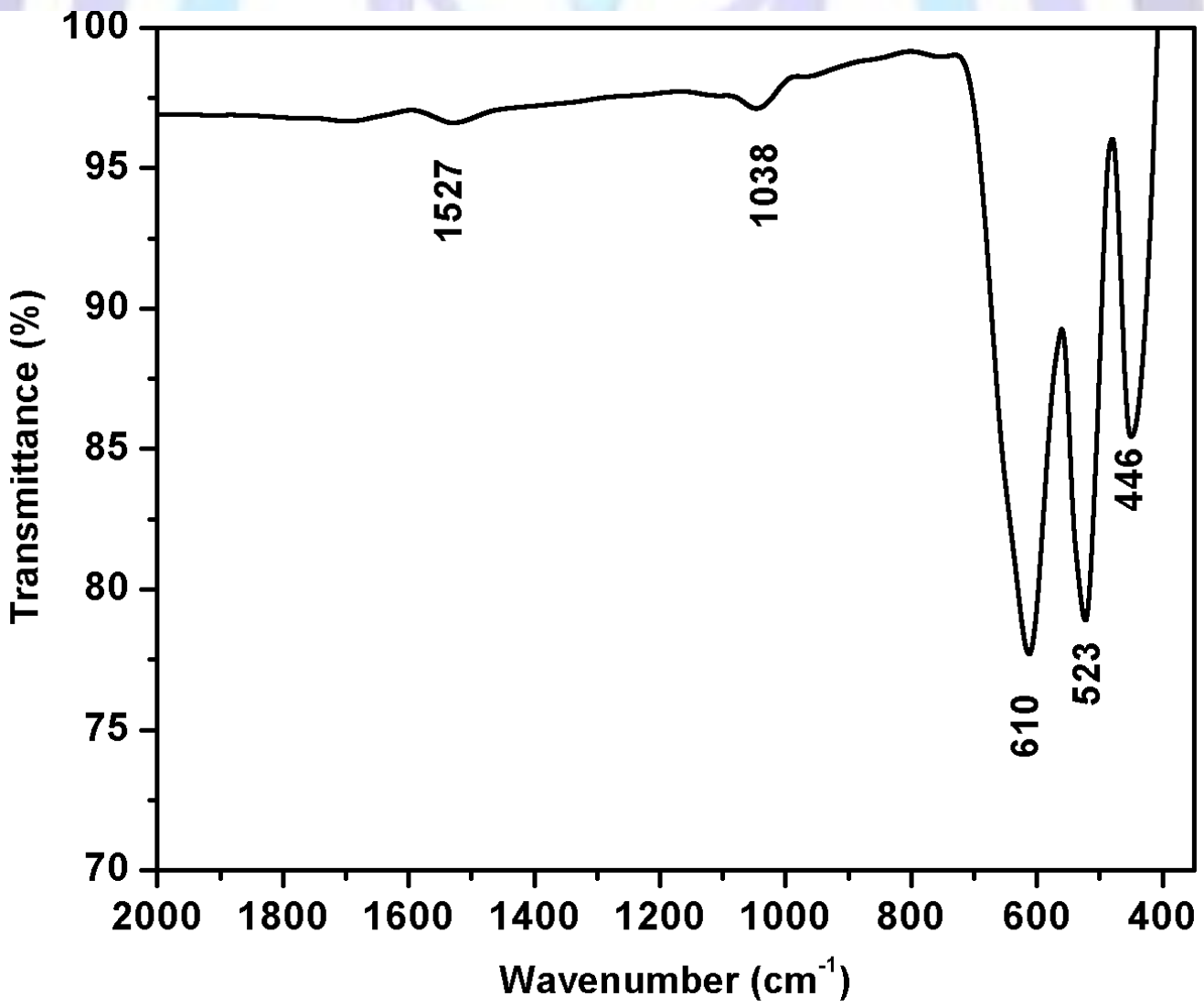

Fig.3 FT-IR spectra of $\mathrm{Mn}_{3} \mathrm{O}_{4}$ nanoparticles 


\section{a}

8

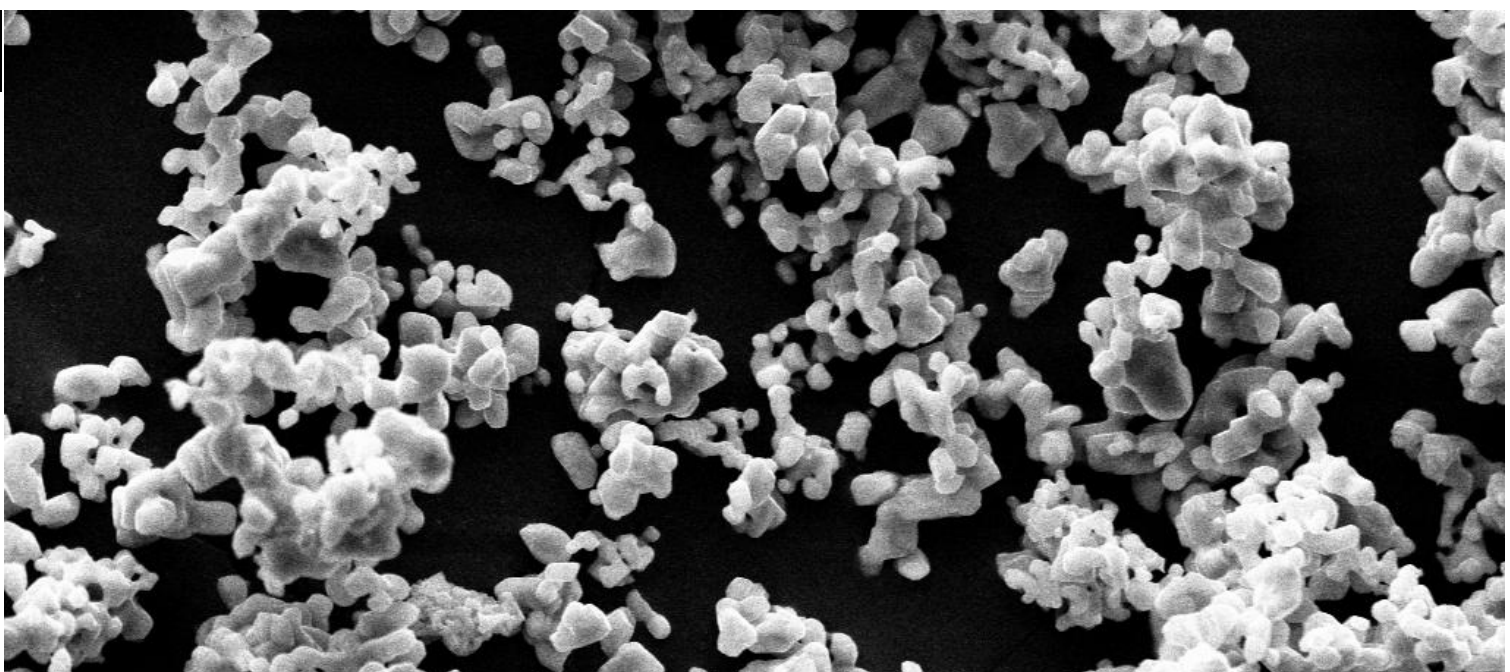

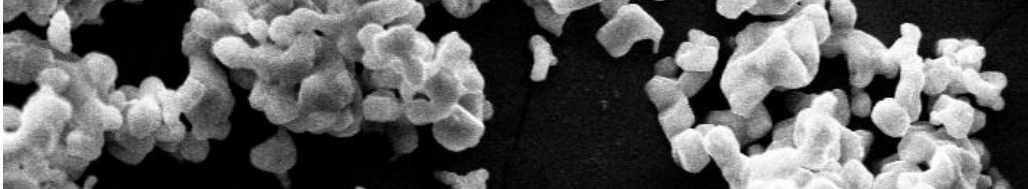

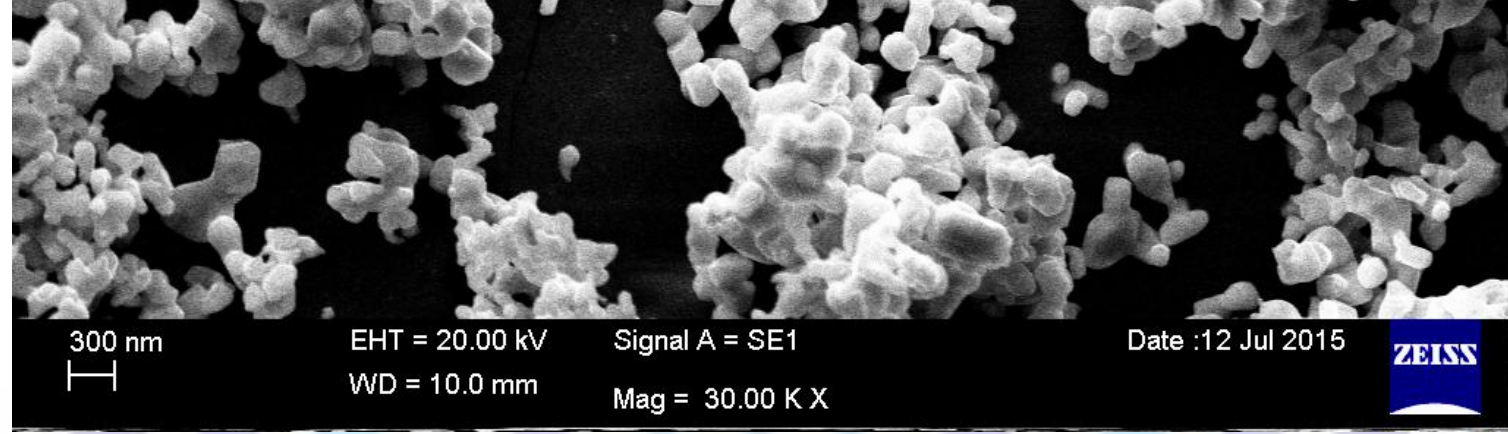

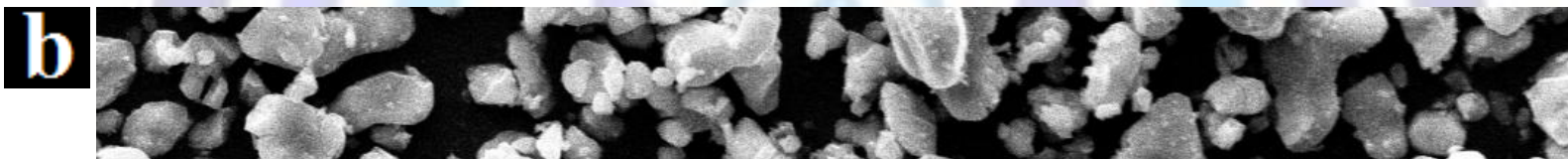
12 (1) 


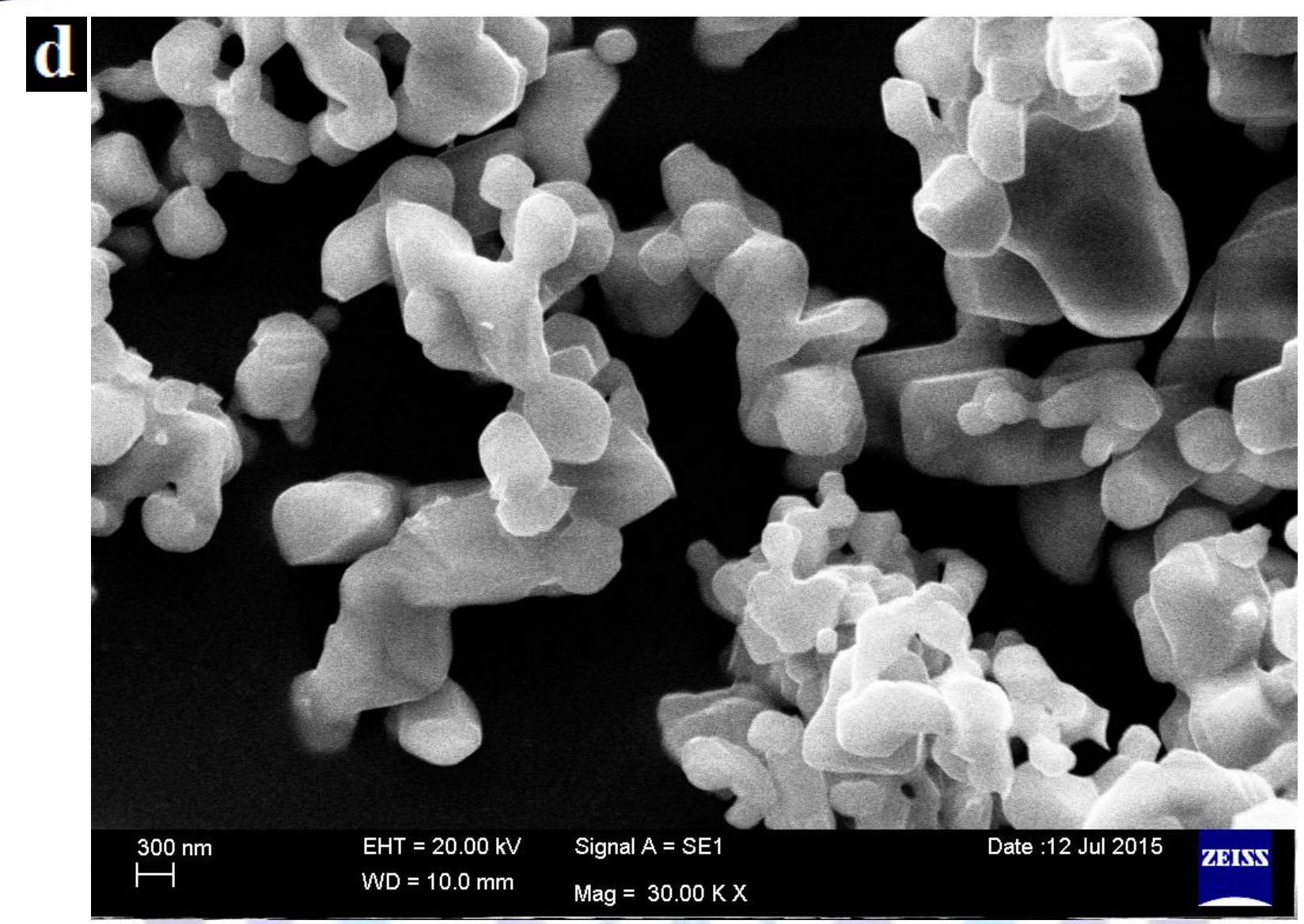

Fig.4 SEM images of $\mathrm{Mn}_{3} \mathrm{O}_{4}$ nanoparticles (a) $1 \mathrm{~h}$ (b\&c) $12 \mathrm{~h}$ (d) $24 \mathrm{~h}$

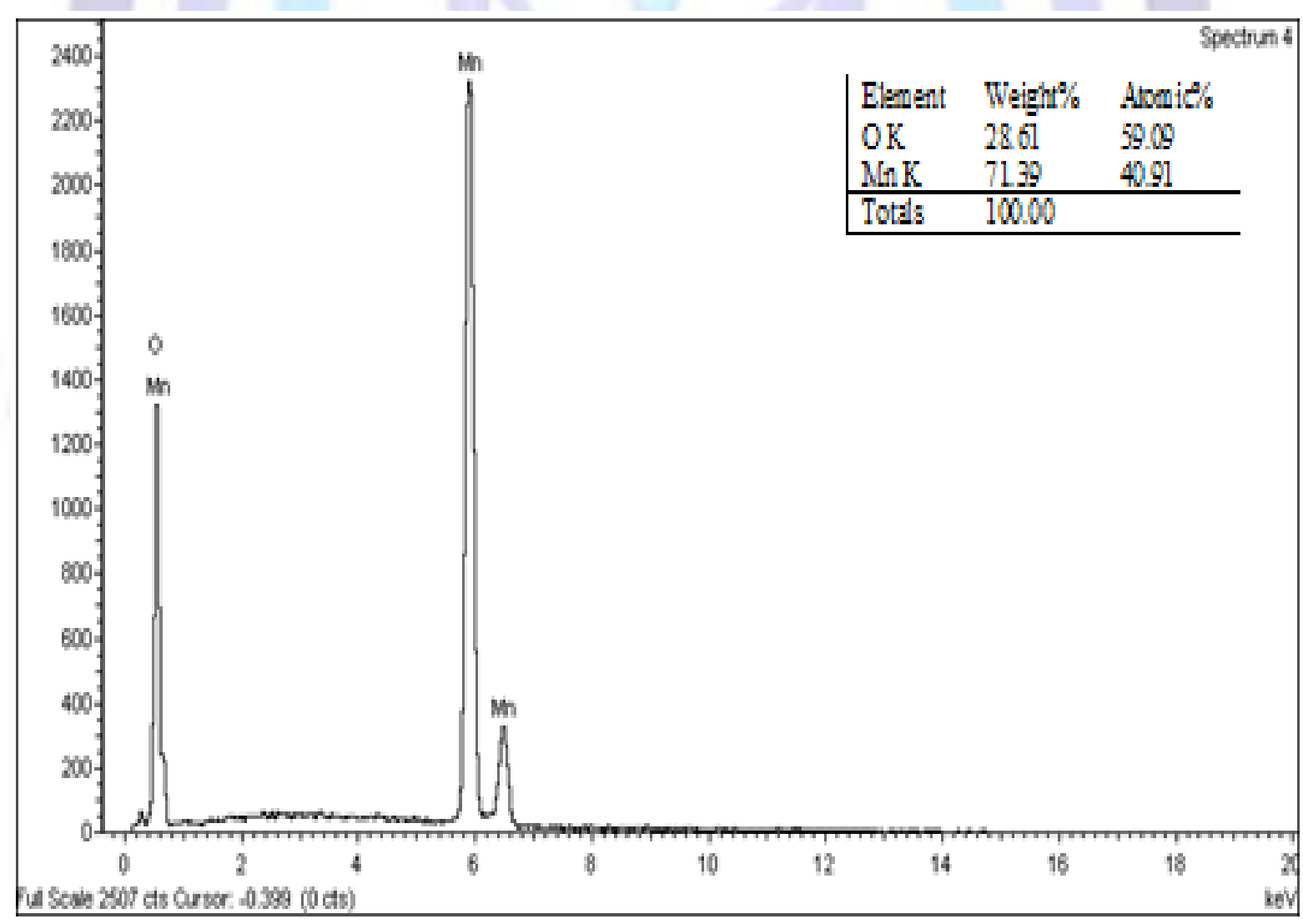

Fig.5 EDAX spectrum of $\mathrm{Mn}_{3} \mathrm{O}_{4}$ nanoparticles 


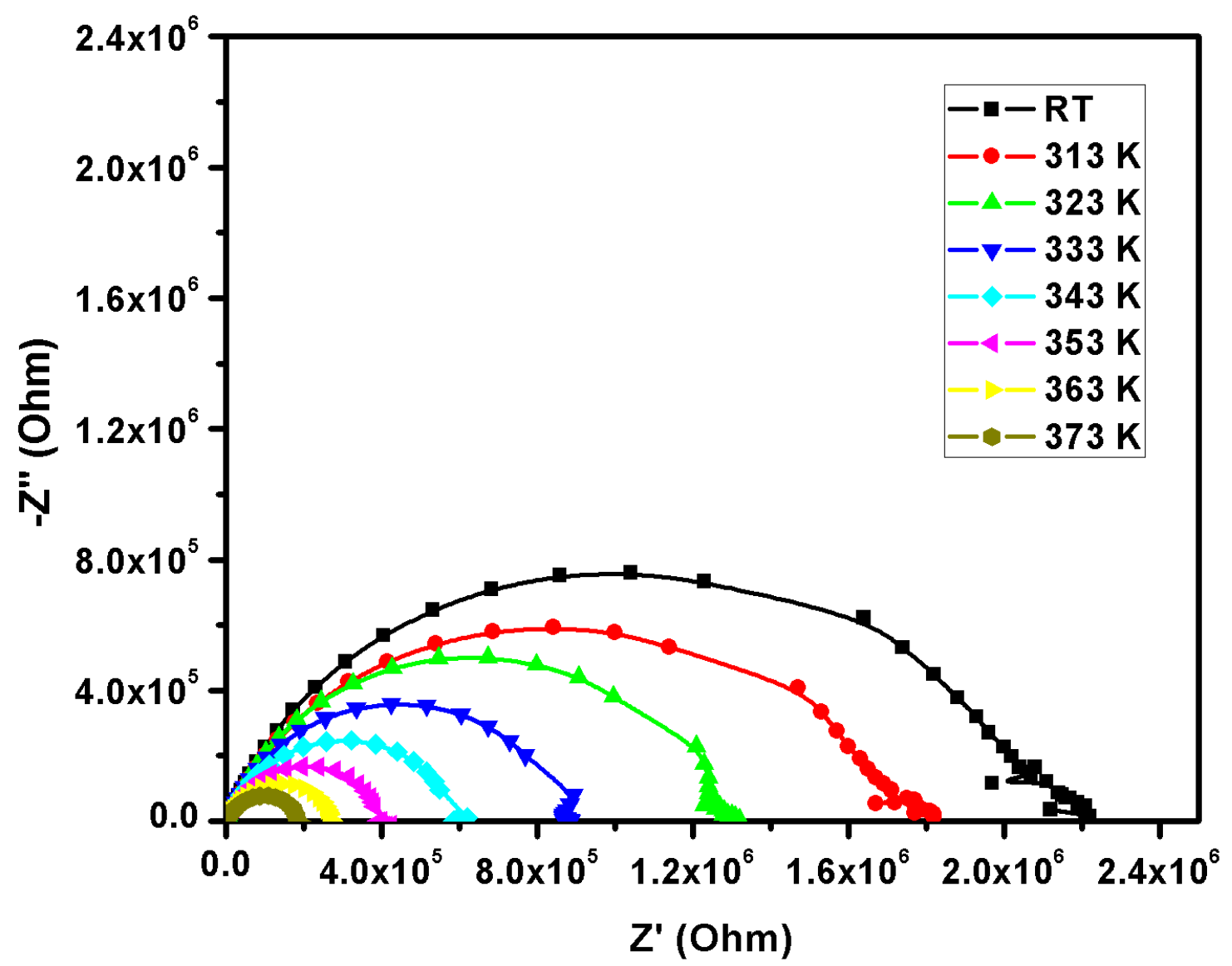

Fig. 6 Cole-Cole plots of $\mathrm{Mn}_{3} \mathrm{O}_{4}$ nanoparticles

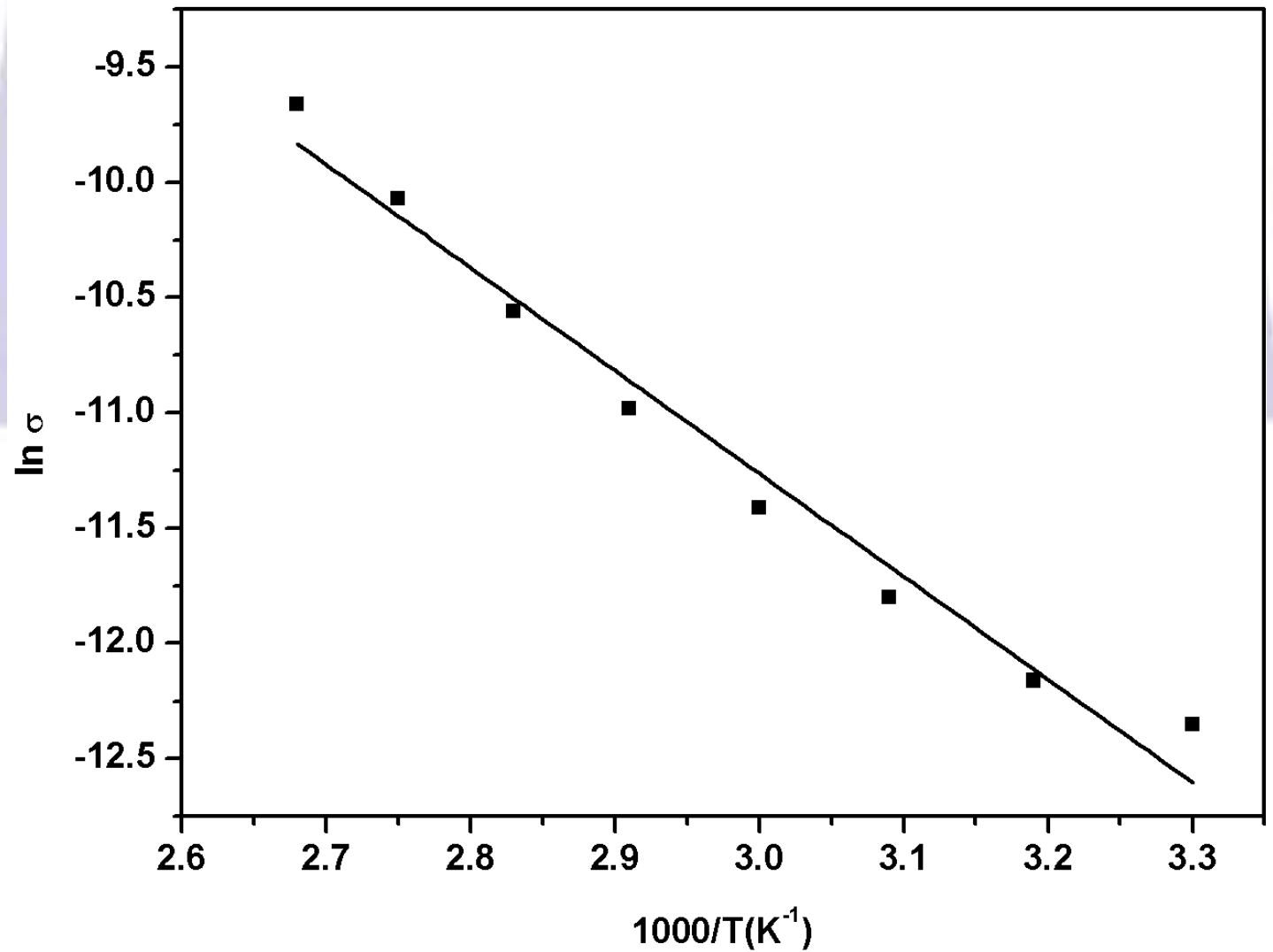

Fig. 7 Temperature dependence of conductivity 


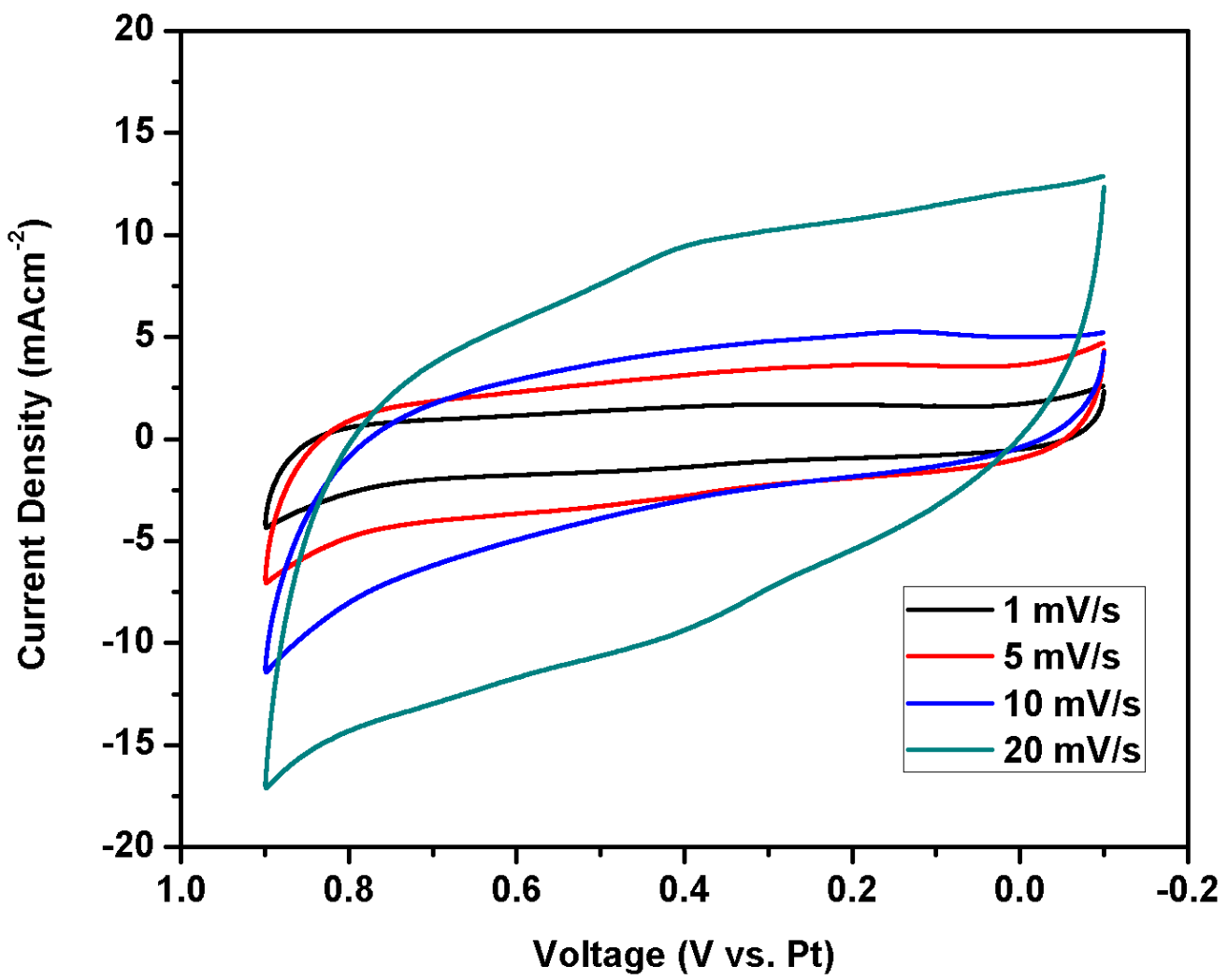

Fig. $8 \mathrm{a}$ The CV curves of $\mathrm{Mn}_{3} \mathrm{O}_{4}$ electrode at different scan rates in the $1 \mathrm{M} \mathrm{Na}_{2} \mathrm{SO}_{4}$ electrolyte in the potential range $-0.1 \mathrm{~V}$ to $+0.9 \mathrm{~V}$

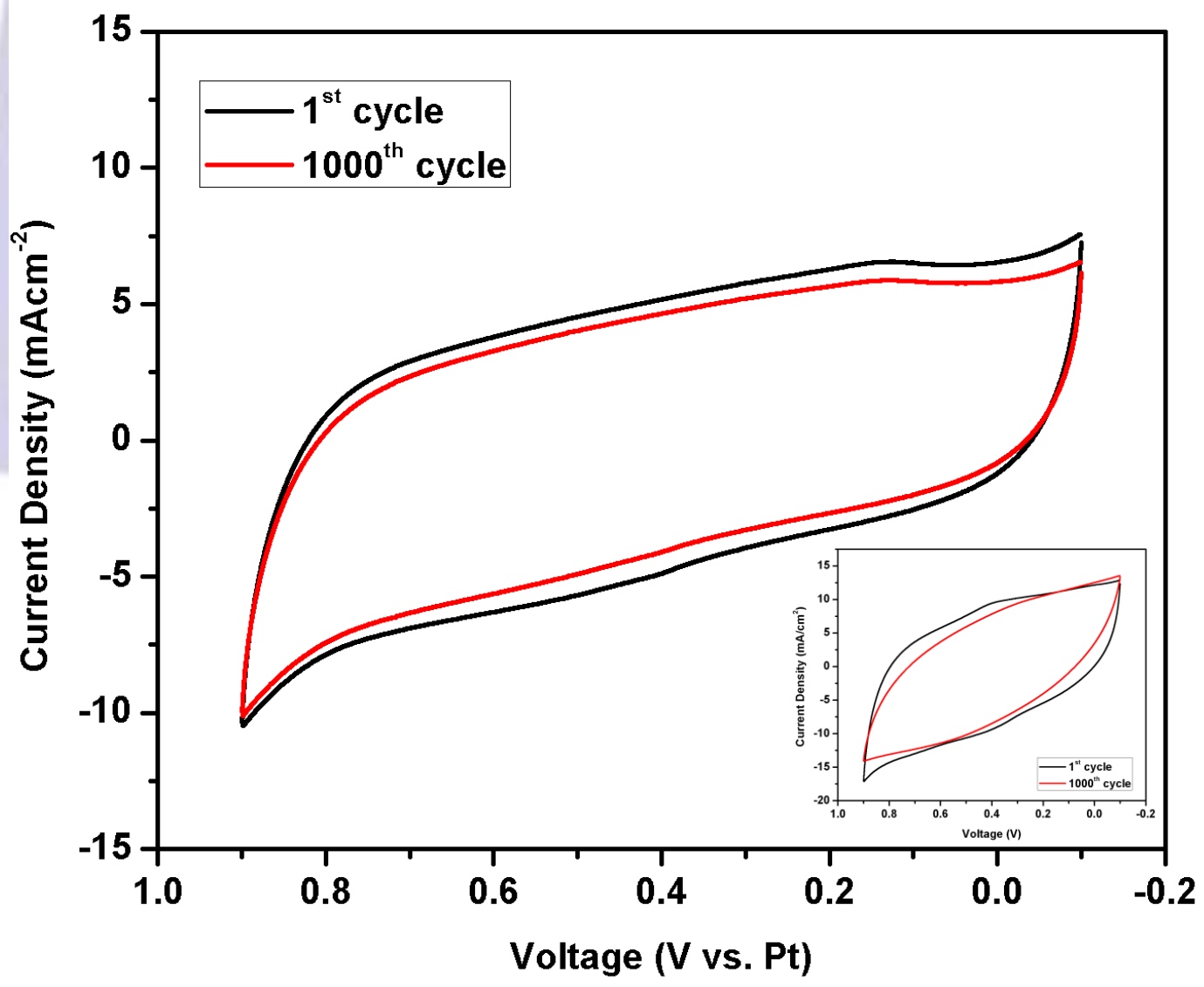

Fig. $8 \mathrm{~b}$ The CV curves of $\mathrm{Mn}_{3} \mathrm{O}_{4}$ for $1^{\text {st }}$ and $1 / 000^{\text {th }}$ cycle at $10 \mathrm{mVs}^{-1}$ and $20 \mathrm{mVs}^{-1}$ (inset) 


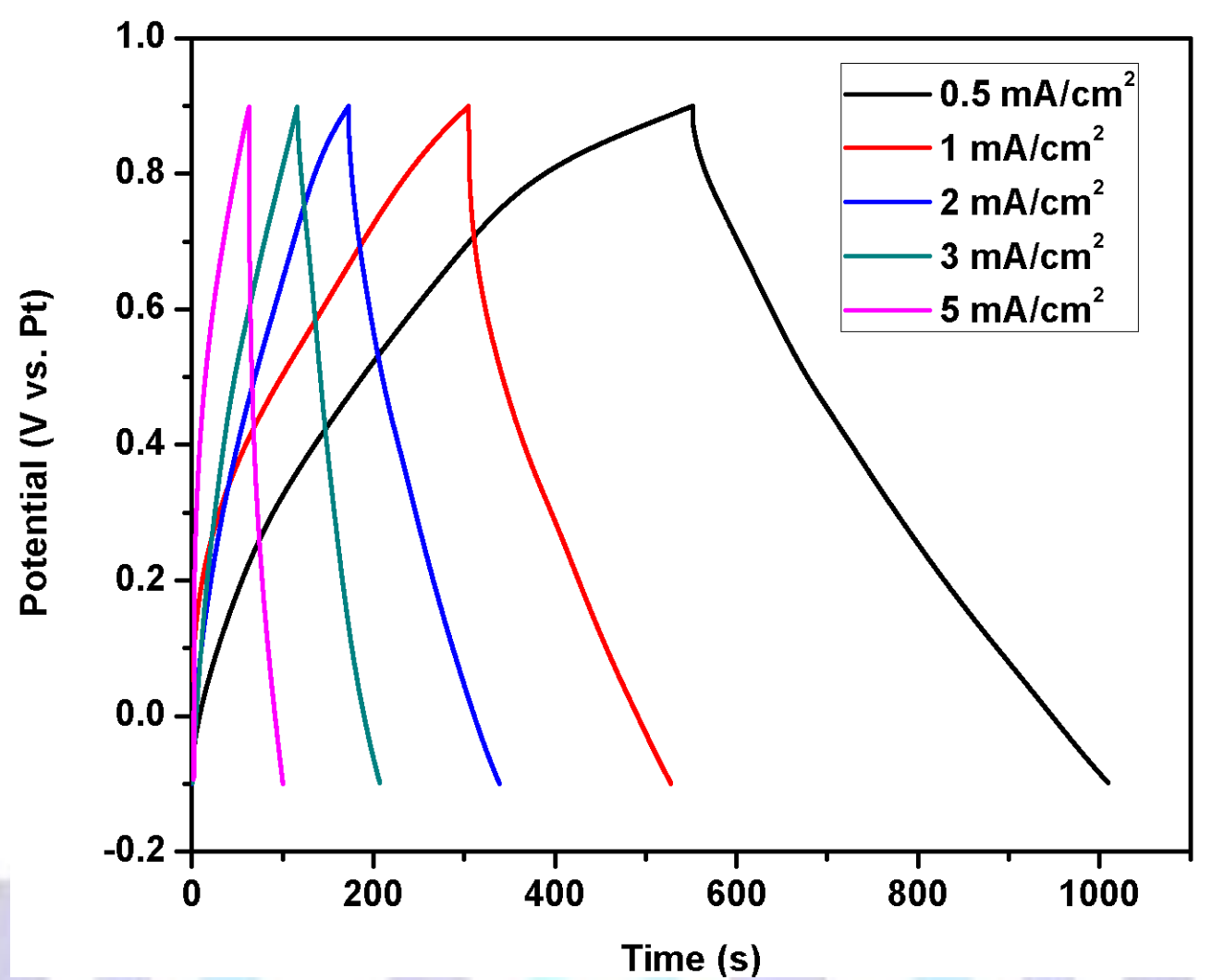

Fig. 9a Galvanostatic charge-discharge curves at different current densities $0.5 \mathrm{mAcm}^{-2}$, $\mathrm{mAcm}^{-2}, 2 \mathrm{mAcm}^{-2}, 3 \mathrm{mAcm}^{-2}$ and $5 \mathrm{mAcm}^{-2}$

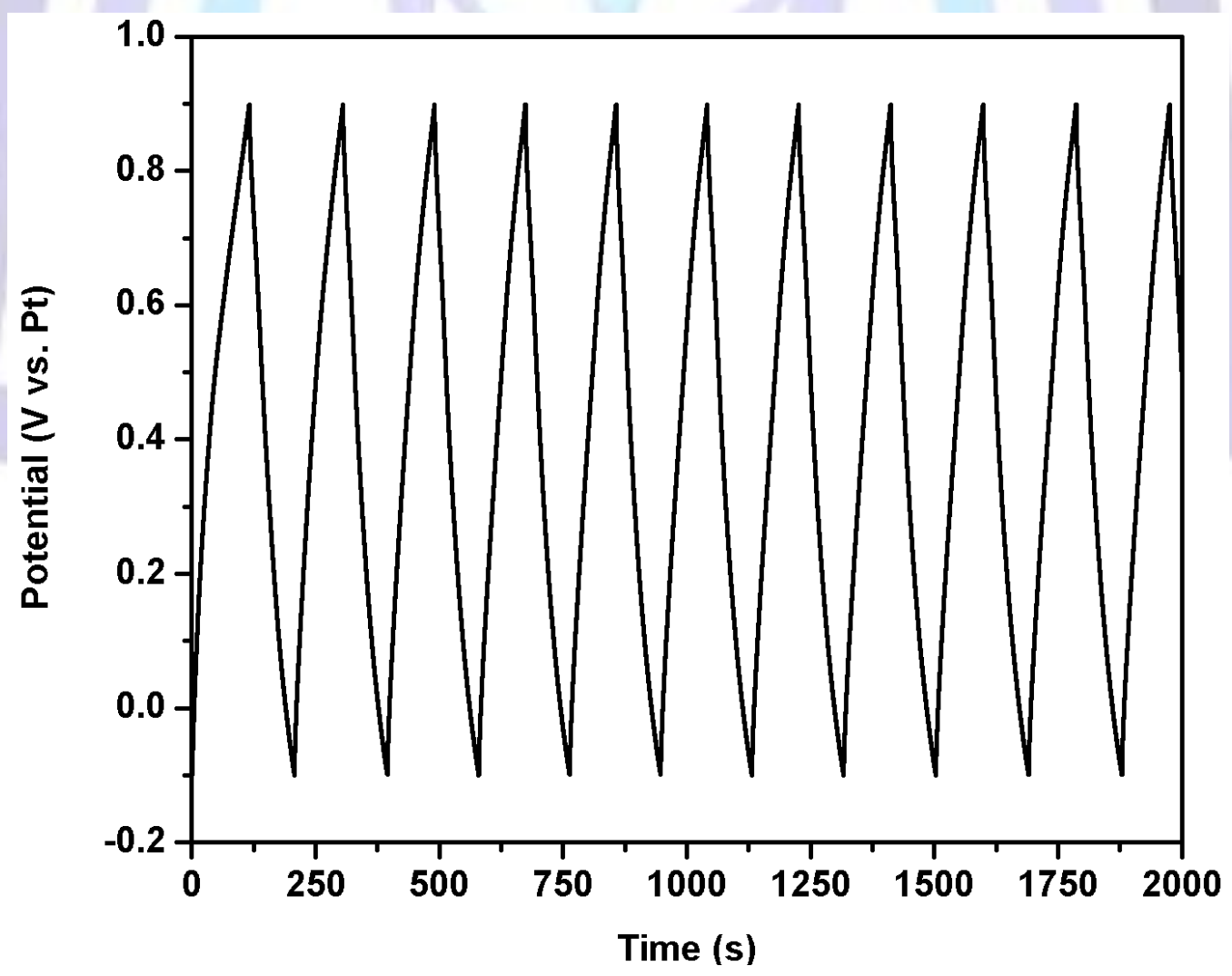

Fig. 9b First 10 charge-discharge cycles of $\mathrm{Mn}_{3} \mathrm{O}_{4}$ nanoparticles in $1 \mathrm{M} \mathrm{Na}_{2} \mathrm{SO}_{4}$ electrolyte at a current density of $3 \mathrm{mAcm}^{-2}$ 


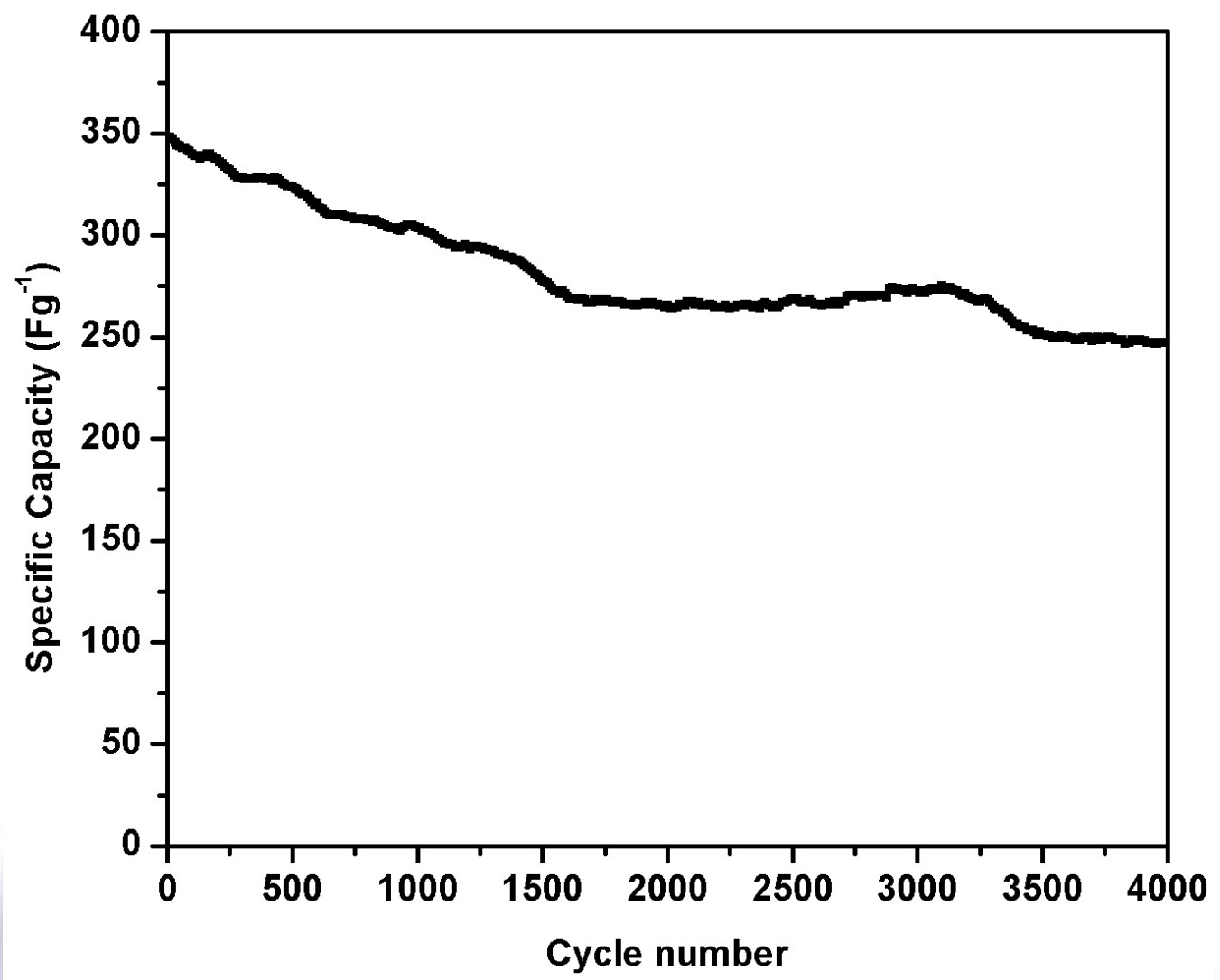

Fig. 9c Specific capacitance with cycle number

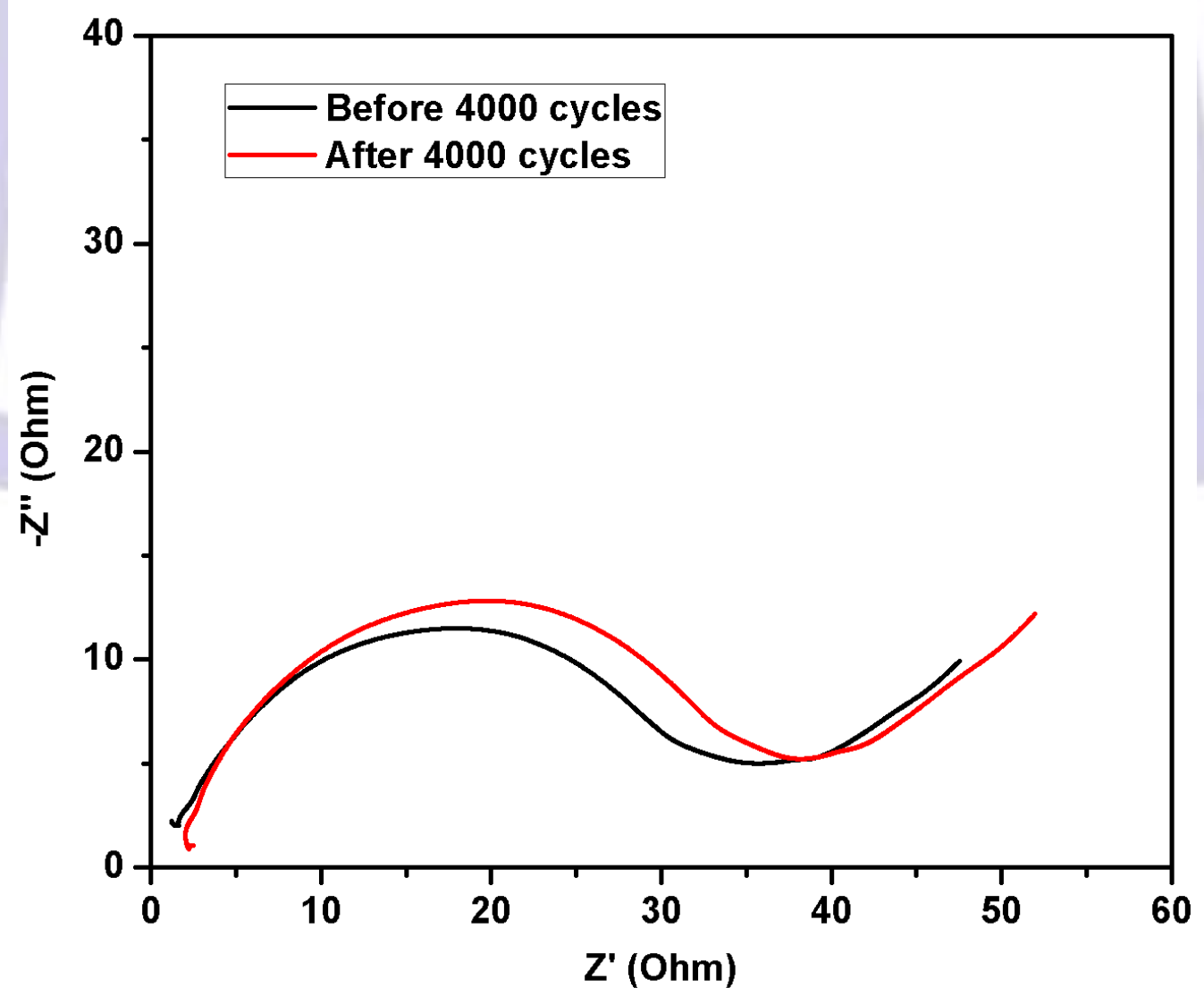

Fig. 10 Electrochemical Impedance Spectra of $\mathrm{Mn}_{3} \mathrm{O}_{4}$ nanoparticles 


\section{REFERENCES}

[1]. Kotz R, Carlen M. “Principles and applications of electrochemical capacitors” Electrochim Acta 45 (2000) 2483-2498.

DOI: 10.1016./S0013-4686(00)00354-6.

[2]. Hui Pan, Jianyi Li and YuanPing Feng "Carbon nanotubes for supercapacitor” Nanoscale Research Letters 5 (2010) 654-668.

DOI: 10.1007/s11671-009-9508-2

[3]. Chuang Peng, Shengwen Zhang, Daniel Jewell, George Z. Chen "Carbon nanotube and conducting polymer composites for supercapacitors" Progress in Natural Science 18 (2008) 777-788.

DOI: 10.1016/j.pnsc.2008.03.002

[4]. Khomenk.Frackowiak Barsukov Béguin "Development of supercapacitors based on conducting polymers" Springer 229 (2006) $41-50$

DOI: 10.1007/1-4020-4812-2-4

[5]. Lokhande C.D, Dubal D.P Dubal, O.S. Joo "Metal oxide thin film based supercapacitors" Current Applied Physics 11 (2011) 255-270

DOI: 10.1016/j.cap.2010.12.001

[6]. Devadas A, Baranton S, Napporn T.W, Coutanceau C "Tailoring of $\mathrm{RuO}_{2}$ nanoparticles by microwave assisted Instant method for energy storage applications" Journal of Power Sources 196 (2011) 4044-4053.

DOI 10.1016/j.jpowsour.2010.11.149

[7]. Linrui Hou, Changzhou Yuan, Long Yang, Laifa Shen, Fang Zhang and Xiaogang Zhang " Urchin like $\mathrm{Co}_{3} \mathrm{O}_{4}$ micorspherical hierarchical superstructures constructed by one dimension nanowires towards electrochemical capacitors" ACS Advances 1 (2011) $1521-1526$.

DOI 10.1039/C1RA00312G

[8]. Han D, Xu P, Jing X, Wang J, Yang P, Shen Q, Liu J, Song D, Gao Z, Zhang M "Trisodium citrate assisted synthesis of hierarchic al $\mathrm{NiO}$ nanospheres with improved supercapacitors performance" Journal of Power Sources 235 (2013) 45-53.

DOI 10.1016/j.jpowsour.2013.01.180

[9]. Wang B, Guan D, Gao Z, Wang J, Li Z, Yang W, Liu L " Preparation of grapheme nanosheets/SnO2 composites by pre reduction followed by in situ reduction and their electrochemical performance" Materials chemistry and physics 141(1) (2013) 1-8.

DOI 10.1016./j.matchemphys.2013.02.052

[10]. Purushothan Reddy B, Sivajee Ganesh K, Jayanth Babu K, Hussain O.M, Julien. C M "Mircrostructure and supercapacitive properties of RF sputtered copper oxide thin films: Influence of O2:Ar ratio" Ionics (2015)

DOI 10.1007/s11581-015-1403-5

[11]. Zhang $X, Y u P$, Zhang $D$, Zhang $H$, Sun $X, M a ~ Y$ "Room temperature synthesis of $\mathrm{Mn}_{3} \mathrm{O}_{4}$ nanoparticles: characterization, electrochemical properties and hydrothermal transformation to $\mathrm{Y}-\mathrm{MnO}_{2}$ nanorods" Materials Letters 92 (2013) 401-404.

DOI: 10.1016/j.matlet..2012.11.022

[12]. Dubal DP, Dhawale DS, Salunkhe RR, Lokhande CD "A novel chemical synthesis of $\mathrm{Mn}_{3} \mathrm{O}_{4}$ thin film and its stepwise conversion into birnessite MnO2 during super capacitive studies" Journal of Electroanalytical Chemistry 647 (2010) 60-65.

DOI: 10.1016/j.jelechem.2010.05.010

[13]. Nagamuthu S, Vijayakumar S, Muralidharan $\mathrm{G}$ "Synthesis of $\mathrm{Mn}_{3} \mathrm{O}_{4} /$ Amorphous carbon nanoparticles as electrode material for high performance supercapacitor applications" Energy and Fuels 27 (2013) 3508-3515.

DOI: 10.1021/ef400212b|energyfuels2013,27 3508-3515

[14]. Xia $\mathrm{H}$, Xiao W, Lai MO, Lu L "Facile synthesis of novel nanostructure $\mathrm{MnO}_{2}$ thin film and their applications in supercapacitors" Nanoscale Res letters 4 (2009) 1035-1040.

DOI 10.1007/s11671-009-9352-4

[15]. Lin He, Geng Zhang, Yuanzhu Dong, Zhenwei Zhang, Shihan Xue, Xingmao Jiang " Polyetheramide Templated Synthesis of Monodisperse $\mathrm{Mn}_{3} \mathrm{O}_{4}$ Nanoparticles with controlled size and study of the electrochemical properties" Nano Micro Letters 6(1) (2014), 38-45.

DOI 10.5101/nml.v6i1.p38-45

[16]. Fatemeh Davar, Masoud Salavati-Niasari, Noshin Mir, Kamal Saberyan, Majid Monemzadeh, Eshagh Ahmadi "Thermal decomposition route for synthesis of $\mathrm{Mn}_{3} \mathrm{O}_{4}$ nanoparticles in presence of a novel precursor" Polyhedron 29(2010) 1747-1753

DOI: 10.1016/j.poly.2010.02.026

[17]. Jiazheng Wang, Ning Du, Hao Wu, Hui Zhang, Jingxue Yu, Deren Yang “ Order-aligned $\mathrm{Mn}_{3} \mathrm{O}_{4}$ nanostructures as super high-rate electrodes for rechargeable lighium-ion batteries" Journal of Power Sources 222 (2013) 32-37.

DOI 10.1016/j.jpowsour.2012.01.094

[18]. Taher Yousefi, Ahmad Nozad Golikand, Mohammad Hossein Mashhadizadeh, Mustafa Aghazadeh " High temperature and low current density synthesis of $\mathrm{Mn}_{3} \mathrm{O}_{4}$ porous nano spheres: characterization and electrochemical properties" Current Applied Physics 12(2012) 544-549. 
DOI: 10.1016/j.cap.2011.08.018

[19]. Vijaya Sankar K, Kalpana D, Kalai Selvan R " Electrochemical Properties of microwave-assisted reflux-synthesized $\mathrm{Mn}_{3} \mathrm{O}_{4}$ nanoparticles in different electrolytes for supercapacitor applications” Journal of Applied Electrochemistry 42 (2012) 463-470.

DOI: 10.1007/s10800-012-0424-2

[20] Lu-Feng Y, Chuang G, Ming-Tao Z, Chao-Fan H, Jiang-Hu C, Ying-Liang L "Synthesis and Electrochemical properties of $\mathrm{Mn}_{3} \mathrm{O}_{4}$ polyhedral nanocrystals" Chinese Journal of Inorganic Chemistry 29(2013) 381-388.

DOI: 10.3969/j.issn.1001-4861.2013.00.026

[21]. H. Jiang, T. Zhao, C.Y. Yan, J. Ma, C. Z. Li " Hydrothemal synthesis of novel $\mathrm{Mn}_{3} \mathrm{O}_{4}$ nano-octahedrons with enhanced supercapacitors performances" Nanoscale 2 (2010) 2195-2198

DOI: 10.1039/c0nr00257g

[22]. Gnana Sundara Raj B, Abdullah M. Asiri, Jerry, Wu J., Sambandam Anandan " Synthesis of $\mathrm{Mn}_{3} \mathrm{O}_{4}$ nanoparticles via chemical precipitation approach for supercapacitor application" Journal of Alloys and Compounds 636(2015) 234-240.

DOI 10.1016/j.jallcom.2015.02.164

[23]. H Jiang, T Zhao, C Yan, J Ma and C Li "Hydrothermal synthesis of novel $\mathrm{Mn}_{3} \mathrm{O}_{4}$ nano-octahedrons with enhanced supercapacitors performances" Nanoscale 2 (2010) 2195-2198

$10.1039 /$ conr00257g

[24]. CM Julien, M. Massot, C. Poinsignon, Spectrochimica Acta A 60(2004) 689-700

[25]. Regmi R, Tackett R, Lawes G. "Suppression of low-temperature magnetic states in $\mathrm{Mn}_{3} \mathrm{O}_{4}$ nanoparticles" Journal of Magnetism and Magnetic Materials 321 (2009) 2296-2299.

DOI: 10.1016/j.jmmm.2009.01.041

[26]. J. Zhao, C. Xu, Y Liu, and Y Qian " crystallite size effects on the raman spectra of $\mathrm{Mn}_{3} \mathrm{O}_{4}$ ” Nanostructured materials 10 (1998) 1331 1335

[27]. Shuang-Yu Liu, Jian Xie, Yun-Xiao Zheng, Gao-Shao Cao, Tie-Jun Zhu, Xin-Bing Zhao "Nanocrystal manganese oxide $\left(\mathrm{Mn}_{3} \mathrm{O}_{4}\right.$, $\mathrm{MnO}$ ) anchored on graphite nanosheet with improved electrochemical Li-storage properties" Electrochimica Acta 66 (2012) 271-278.

DOI 10.1016/j.electacta.2012.01.094

[28]. Ghodbane O, Pascal J L, Fraisse B, Favier F. "Structural in situ study of the Thermal behavior of Manganese

dioxide material:Toward selected electrode materials for supercapacitors" ACS applied materials and Interfaces 2 (2010) 3493-3505

10.1021/am100669k

[29]. Dubal DP, Dhawale DS, Salunkhe RR, Fulari VJ, Lokhande CD “ chemical synthesis and characterization of $\mathrm{Mn}_{3} \mathrm{O}_{4}$ thin films for supercapacitor application” Journal of Alloyed Compounds 497 (2010) 166-170

10.1016/j.jallcom.2010.02.182

[30]. H. Dhaouadi, O Ghodbane, F Hosni and F Touati (2012) ISRN spectroscopy 2012

DOI: $10.5402 / 2012 / 706398$

[31]. Deepak P. Dubal and Rudoff Holze "A successive ionic layer adsorption and reaction(SILAR) method to induce $\mathrm{Mn}_{3} \mathrm{O}_{4}$ nanospots on CNTs for supercapacitors" New Journal of Chemistry 37 (2013) 403-408.

$10.1039 / \mathrm{c} 2 \mathrm{nj} 40862 \mathrm{~g}$ 